Research papers

\title{
Spring 2009 water mass distribution, mixing and transport in the southern Adriatic after a low production of winter dense waters
}

\author{
Ana E. Rice ${ }^{\mathrm{a}, *}$, Jeffrey W. Book ${ }^{\mathrm{a}}$, Sandro Carniel ${ }^{\mathrm{b}}$, Aniello Russo ${ }^{\mathrm{c}, \mathrm{d}}$, Katrin Schroeder ${ }^{\mathrm{e}}$, \\ Warren T. Wood ${ }^{\mathrm{a}}$ \\ a Naval Research Laboratory, Code 7332, Bldg. 1009, Room B137, Stennis Space Center, MS 39529-5004, USA \\ ${ }^{\mathrm{b}}$ CNR - National Research Council of Italy, ISMAR - Marine Sciences Institute in Venezia, Castello 2737/F, 30122 Venice, Italy \\ c DISVA, Universitá Politecnica delle Marche, Via Brecce Bianche, 60131 Ancona, Italy \\ ${ }^{\mathrm{d}}$ CNR - National Research Council of Italy, ISMAR - Marine Sciences Institute in Bologna, Via Pietro Gobetti 101, 40129 Bologna, Italy \\ ${ }^{\text {e }}$ CNR - National Research Council of Italy, ISMAR - Marine Sciences Institute in La Spezia, Forte Santa Teresa, 19032 Pozzuolo di Lerici (SP), Italy ${ }^{1}$
}

\section{A R T I C L E I N F O}

\section{Article history:}

Received 2 November 2012

Received in revised form

7 March 2013

Accepted 17 April 2013

Available online 21 May 2013

Keywords:

Southern Adriatic Sea

Mixing

Frontal region

Water masses

Intrusions

Seismic oceanography

\begin{abstract}
A B S T R A C T
Enhanced mixing of North Adriatic Dense Water (NAdDW) occurs in a strong frontal region as this cold and fresh intermediate water enters the southern Adriatic basin and meets warm and salty Modified Levantine Intermediate Water (MLIW) coming from the Ionian Sea. This study examines how NAdDW was mixed and transformed as it traveled southward from the Gargano to the Bari region and investigates the pathway and intrusion patterns of MLIW in late winter/spring 2009. Hydrographic data are analyzed to compute source water fractions via a least-squares analysis method and combined with ADCP data to compute source water volume fluxes. Results show that despite an anomalous low year for NAdDW production in the Adriatic, a warmer, fresher and lighter version of traditional NAdDW (i.e. 2009 NAdDW) endured its journey from Gargano to Bari. In the Gargano region, 2009 NAdDW (with fractions up to $80-90 \%$ ) traveled southward in a non-continuous thin, dense vein between $35 \mathrm{~m}$ and $100 \mathrm{~m}$ isobaths, with diluted cores $(>50 \%$ ) extending to $140 \mathrm{~m}$ depth, and with fluxes of $-0.05 \mathrm{~Sv}$, to the southeast, south of Palagruža Sill. Near the sill, 2009 NAdDW was further mixed and diluted with MLIW and surface water. By the time it reached the Bari region, the 2009 NAdDW fraction in the water column was reduced to about 20\%. MLIW intrusions observed over the Sill and in northern sections of the study area suggest a splitting of MLIW pathways (stemming from the main South Adriatic rim pathway) towards the central Adriatic. Source water fraction results combined with velocity and seismic oceanography data show that eddies in the study area are one mechanism for the generation of MLIW intrusions towards the northwest.
\end{abstract}

(c) 2013 Elsevier Ltd. All rights reserved.

\section{Introduction}

The flow of dense water off shallow continental shelves and the consequent mixing with intermediate and abyssal waters in the deep ocean are important processes that contribute to water-mass formation, shelf to deep ocean material transfer, and the ventilation of oceanic intermediate and deep water layers (Ivanov et al., 2004; Vilibić and Supić, 2005). The formation of dense water in

Abbreviation: NAdDW, North Adriatic Dense Water; LIW, Levantine Intermediate Water; MLIW, Modified Levantine Intermediate water; ADW, Adriatic Deep Water; EMDW, Eastern Mediterranean Deep Water; SAP, Southern Adriatic Pit; SW, Surface Water; MS, Micro Structure; LADCP, Lowered Acoustic Doppler Current Profiler.

* Corresponding author. Tel.: +1 228688 5650; fax: +1 2286884149.

E-mail addresses: Ana.Rice.ctr@nrlssc.navy.mil, anaerice@gmail.com (A.E. Rice), Jeff.Book@nrlssc.navy.mil (J.W. Book), sandro.carniel@ismar.cnr.it (S. Carniel), a.russo@univpm.it (A. Russo), katrin.schroeder@ismar.cnr.it (K. Schroeder), Warren.Wood@nrlssc.navy.mil (W.T. Wood).

${ }^{1}$ Now at CNR-ISMAR, Venezia shallow shelves occurs in the winter months as a result of cooling, evaporation, and surface layer freezing. In the search of water of equal density, shelf generated dense flows descend down the continental slope in the form of near-bottom gravity currents or intermediate-depth intrusions, and mix with ambient oceanic waters.

Despite its intermittent nature, dense water formation and cascading has been detected in a number of areas of the world's oceans. In the polar latitudes, the generation of dense water and overflow has been observed in the Weddell Sea (Foster and Carmack, 1976; Baines and Condie, 1998), in the Ross Sea (Russo et al., 2011), and in the Barents Sea (Blindheim, 1989), among other regions. In mid-latitudes, Talley et al. (2003) made direct observations of the process in The Peter the Great Bay, Sea of Japan in the winter of 2001 and concluded that cascading may be a primary ventilation mechanism for regenerating bottom waters at this location during cold winters. The Gulf of Lyons (Canals et al., 2006), in the western Mediterranean Sea, the Celtic Sea (Cooper and Vaux, 1949) and the Rockall Bank (Ellett, 1968) and Malin Shelf 
(Hill et al., 1988), located west of the British Isles, are other locations where dense water formation and cascading on the continental slope has been detected. In the tropics and subtropics, dense overflows have been observed in the south-eastern continental shelf of North America (Yoder and Ishimaru, 1989), northern Gulf of California (Lavin et al., 1995), and offshore of Australia in Jervis Bay (Symonds and Gardiner-Garden, 1994).

As a result of geographical location, bottom bathymetry, and climatic conditions, the Adriatic Sea is another location within the temperate latitudes that is favorable for dense water generation and cascading mechanisms. In the winter months two dense water formation sites exist there: the South Adriatic Pit (SAP) (max. $1200 \mathrm{~m}$ deep) and the shallow (50-100 m) northern Adriatic shelf. In the SAP, open ocean convection produces Adriatic Deep Water (ADW) (Cardin et al., 2011). This source water mass usually represents the main component of the Eastern Mediterranean Deep Water (EMDW) (Artegiani et al., 1993) and is the warmest $\left(T=\sim 13.3^{\circ} \mathrm{C}\right)$ and most saline $(S=\sim 38.6)$ water mass of Adriatic origin. It flows into the Ionian Sea via the Otranto Strait and spreads over the Eastern Mediterranean bottom layer (Pollak, 1951). In a study of water mass property variability in the last two decades (1990-2009), Cardin et al. (2011) noted high interannual variability of ADW properties with influences of the Eastern Mediterranean Transient (EMT) manifested in the vertical temperature and salinity patterns. Attributed to changes in meteorological anomalies and circulation patterns, the EMT was a major climatic event in the 1990s that caused a shift in EMDW origin from cooler and fresher Adriatic Sea waters to warmer and saltier Aegean Sea waters (Roether et al., 1996; Vilibić et al., 2012).

On the northern shelf, North Adriatic Dense Water (NAdDW) is formed by strong surface cooling and evaporation associated with north-easterly Bora wind episodes (Vilibić and Orlić, 2002; Vilibić, 2003). These storms cause increased surface density and subsequent vertical mixing in the water column (Gačić et al., 2001, Chapter 1: overview), which encourages the formation of this cold and fresh (primarily due to Po River runoff) dense water mass (Fig. 1, north and central Adriatic inset). In the late winter to early spring NAdDW is transported to the south forming a dense vein along the bathymetric slope (Artegiani and Salusti, 1987; Bignami, 1990; Vilibić, 2003). In the vicinity of the Palagruža Sill, NAdDW abruptly encounters warmer, saltier and typically less dense Modified Intermediate Levantine Water (MLIW) (Wust, 1961; Malanotte-Rizzoli and Hecht, 1988), coming from the Ionian sea, through Otranto Strait and circulating in the deeper southern basin (Fig. 1). Hydrographic data and direct measurements suggest that the permanent cyclonic circulation (Southern Adriatic Gyre) of MLIW is controlled by the topography of the SAP (Poulain, 2001; Manca et al., 2002).

NAdDW and MLIW water masses exhibit opposite temperature and salinity properties, and thus a strong temperature and salinity frontal region of enhanced mixing is formed as they meet. Similarly to ADW, the generation, intensity and water properties of these source waters vary greatly on interannual and decadal scales (Cardin et al., 2011). The water mass properties of MLIW in a given year are dependent on conditions outside of the Adriatic, in the Levantine basin where the Levantine Intermediate Water (LIW) is formed. On the other hand, the formation of NAdDW depends on the impacts of river discharges, the surface salinity and the intensity of winter heat losses at the air-sea interface (Gačić et al., 2001, Chapter 1: overview). Characteristic NAdDW temperature, salinities and densities range from $\sim 9.0 \leq T \leq 11.35^{\circ} \mathrm{C}$, $\sim 38.30 \leq S \leq 38.50$, and $\sim 29.35 \leq \sigma_{t} \leq 29.51$ (Orlić et al., 1992; Supić and Vilibić, 2006; Wang et al., 2006-2007), respectively. Similarly, MLIW salinity averages are $\sim 38.75$, but can be as high as 38.90 (Vilibić and Orlić, 2001; Cardin et al., 2011).

Once NAdDW fills the Jakuba Pit in the central Adriatic and meets MLIW south of the Palagruža Sill, it continues to travel south to the SAP where it influences the generation of ADW (Vilibic and Supić, 2005) and hence the ventilation of EMDW. In years where it is denser than the surrounding waters, NAdDW cascades down the Bari Canyon. This process has been documented by a number of observational (e.g. Trincardi et al., 2007; Turchetto et al., 2007) and numerical studies (e.g. Rubino et al., 2012).

In the spring of 2009 a comprehensive hydrographic data set of temperature, salinity and current velocity was collected during three different research cruises mostly in the vicinity of the NAdDW and MLIW frontal region in the southern Adriatic basin. In addition, seismic data from the relatively new seismic oceanography technique (Holbrook et al., 2003; Ruddick et al., 2009; Carniel et al., 2012) were collected in one of the cruises. The aim of this paper is to analyze these data to examine how NAdDW was mixed and transformed as it traveled southward in the southern Adriatic, from the Gargano Promontory to the Bari region (Fig. 1), and to investigate the pathway and intrusion patterns of MLIW. Analysis of the distribution and dilution of source waters and estimates of source water volume fluxes are computed to accomplish this goal. The paper is divided into five sections. In Section 2, data sources are described. In Section 3 temperature-salinity (T-S) characteristics are analyzed, spring 2009 water masses are defined, and a least-square water fraction analysis technique, based on Vilibić and Orlić (2001) method is applied to the data. In addition, the seismic oceanography method is briefly introduced and the methodology for computing source water fluxes is discussed. In Section 4, results of water mass distribution are presented, March 2009 mass transport fluxes are computed and analyzed, and an intrusion analysis using seismic data is discussed. The conclusions follow in Section 5.

\section{Data sources}

In the late winter, early spring of 2009 scientists from the CNRInstitute of Marine Science (ISMAR) conducted three consecutive research cruises aboard the Italian National Research Council (CNR) R/V Urania in the Adriatic Sea: VELTURO9 (February 24March 2; Bortoluzzi et al., 2009), ADRIASEISMIC in collaboration with the US Naval Research Laboratory and the University of Durham (March 3-March 15), and IMPACT09 (March 19-March 26; Langone et al., 2010). In all three field studies, temperature and salinity data were collected using a Conductivity-TemperatureDepth (CTD) SBE911Plus profiler on a rosette. Temperature measurements were performed with an accuracy of $0.001{ }^{\circ} \mathrm{C}$ using a Seabird Electronics (SBE 3plus) sensor, while conductivity (from which salinity PSS-78 was derived) was measured using an SBE 4 sensor with an accuracy of $0.0003 \mathrm{~S} / \mathrm{m}$. Vertical casts were sampled at $24 \mathrm{~Hz}$ with a CTD-rosette vertical speed of $1 \mathrm{~m} / \mathrm{s}$.

Fig. 1 shows the CTD cast locations for VELTUR09 (black triangles), ADRIASEISMIC (red circles) and IMPACT09 (blue diamonds). In addition to CTD data, during the ADRIASEISMIC field study, temperature and salinity data were also collected using an MSS90-D1 free-falling microstructure profiler (red squares in Fig. 1). These measurements were acquired off the ship stern with the vessel proceeding at about 1 knot speed. A total of 5-10 microstructure (MS) profiles were collected at most of these stations. However for the purpose of the present analysis, mean temperature and salinity profile values are used. A salinity bias of 0.05 psu in all MS measurements after March 8, 2009 was found from comparison of CTD and MS data. The likely reason for this bias was contamination of the MS probe while resting on the ship deck, particularly between March 6 and 8, when a strong storm caused all science to cease and the ship to take shelter. All MS profiles taken after March 8 were corrected for the salinity bias. Seismic data were collected along 14 lines during ADRIASEISMIC. 


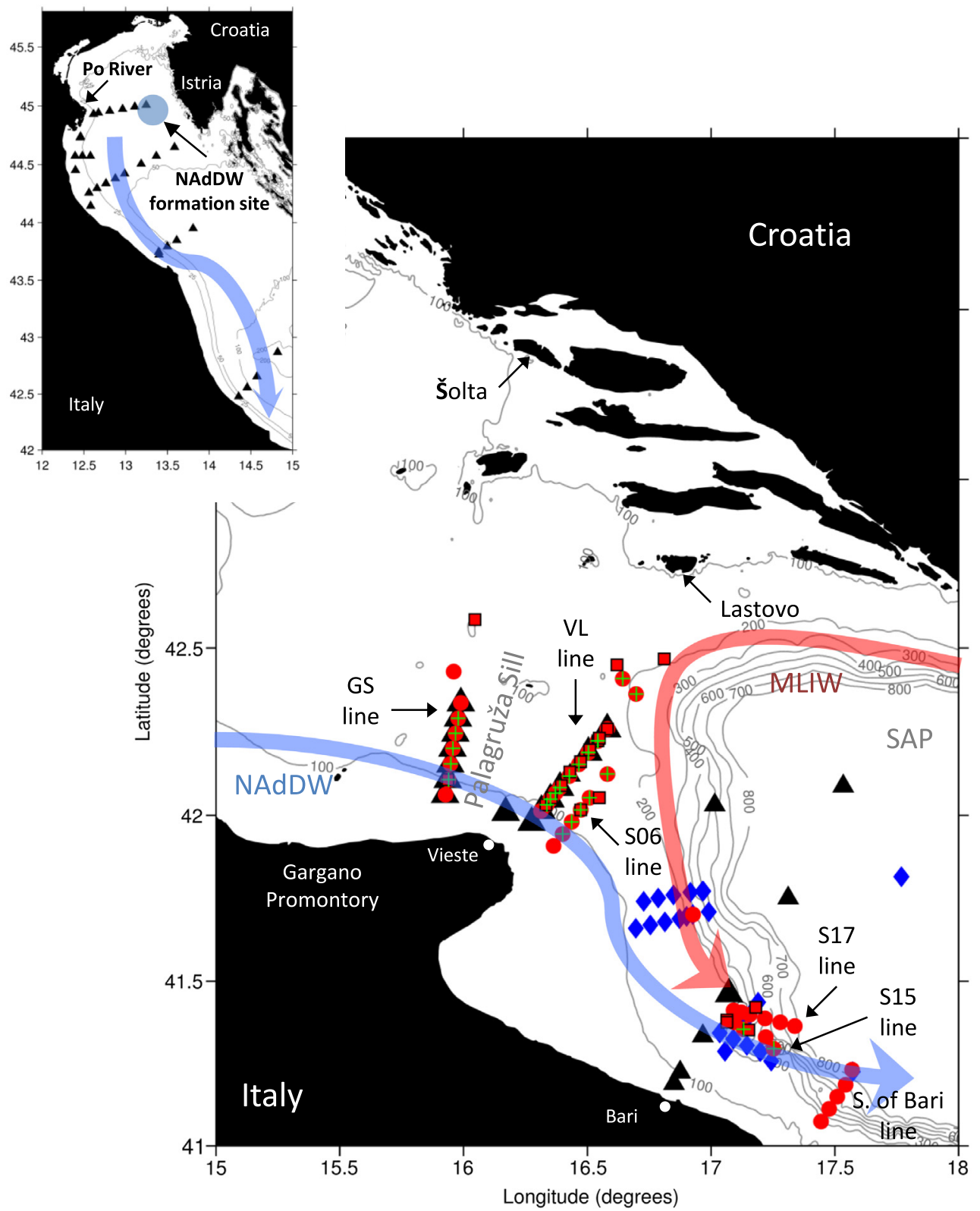

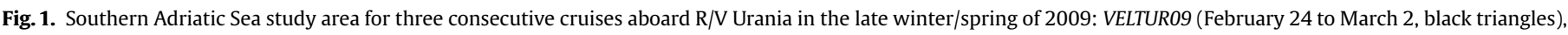

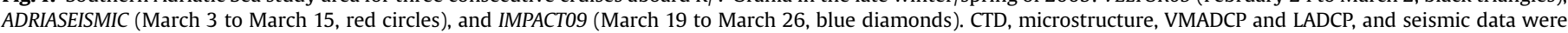

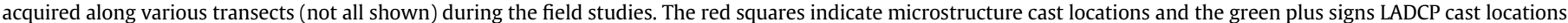

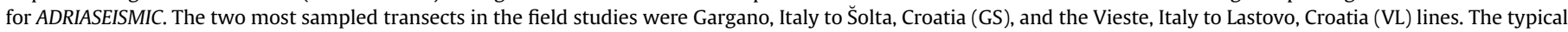

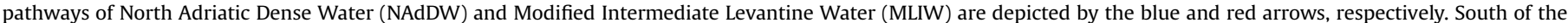

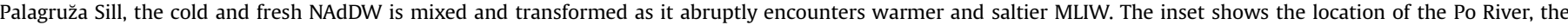

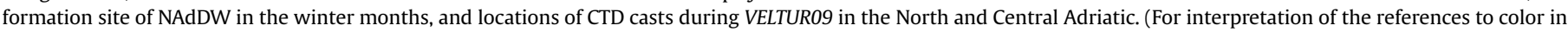
this figure legend, the reader is referred to the web version of this article.)

However only data collected on March 11 along the VL line (Fig. 1) are discussed in this paper.

Current velocity measurements were acquired during ADRIASEISMIC from two Vessel Mounted (VM) Acoustic Doppler Current Profilers (ADCPs), as well as a Lowered ADCP (green plus signs in Fig. 1). The VMADCPs, which operated along the entire cruise track, were a Teledyne Ocean Surveyor (OS), $75 \mathrm{kHz}$, and a Teledyne Workhorse $(\mathrm{WH}), 300 \mathrm{kHz}$. The bin size for the 0575 instrument was $16 \mathrm{~m}$, while for the WH300, $4 \mathrm{~m}$. The LADCP used was an RDI Workhorse $300 \mathrm{kHz}$ with $5 \mathrm{~m}$ bin size and a range of about $100 \mathrm{~m}$. The VMADCP data were processed using the University of Hawaii's, CODAS Software System (version 3), which allowed data extraction, assignment of coordinates, editing, and data correction for errors in the value of sound velocity in the water, and misalignment of the instrument with respect to the axis of the ship (Firing and Ranada, 1995). Lastly, it is worth noting that the two most sampled lines in these three field studies were the historically previously sampled Gargano, Italy to Šolta, Croatia (GS) (Martin et al., 2009), and Vieste, Italy to Lastovo, Croatia (VL) lines (see Fig. 1).

\section{Methods}

\subsection{T-S characteristics and water mass fraction analysis}

Fig. 2a is a temperature-salinity diagram of the CTD and MS datasets collected during the VELTUR09 (black data points), ADRIASEISMIC (red points) and IMPACT09 (blue points) field studies in 
a

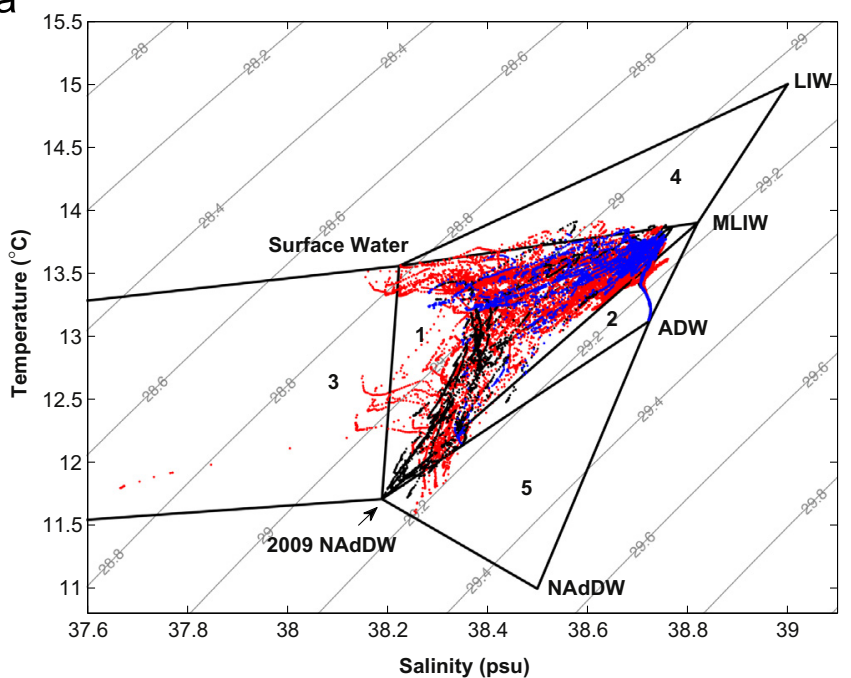

b

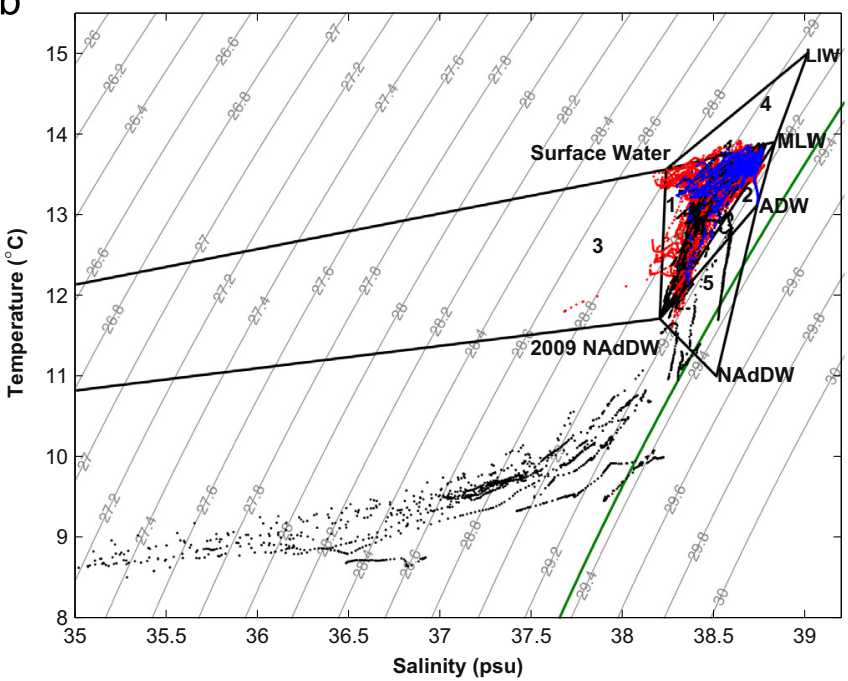

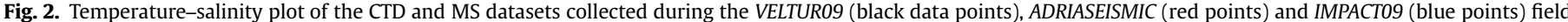

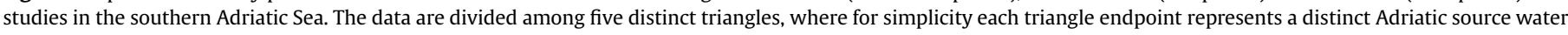

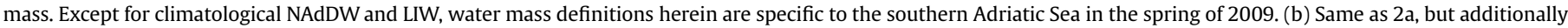

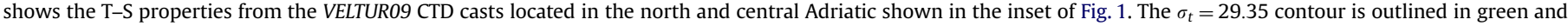

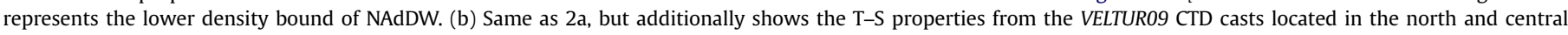

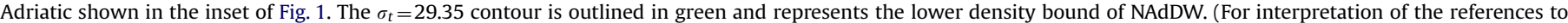
color in this figure legend, the reader is referred to the web version of this article.)

the southern Adriatic. Fig. $2 \mathrm{~b}$ additionally shows the T-S properties of CTD casts collected in the northern and central Adriatic during the VELTURO9 cruise (see Fig. 1 inset for cast locations). Measurements were processed to $1 \mathrm{~m}$ intervals at all stations, so each data point in the figure represents the T-S properties at a specific depth of the water column.

In T-S space, water masses are made up of a small cluster of T-S properties over a small range in temperature and salinity. However for simplicity a single point is used here to define distinct Adriatic source water masses. For reference, we use the climatological NAdDW $\left(T=11.0^{\circ} \mathrm{C} ; \quad S=38.5 ; \quad \sigma_{t}=29.51\right)$ and LIW $\left(T=15.0 ; S=39.0 ; \sigma_{t}=29.10\right)$ definitions depicted by Orlić et al. (1992) and Stratford and Williams (1997), respectively. All other water mass definitions in Fig. 2 are specific to the southern Adriatic in the spring of 2009.

The generation, intensity and water properties of the source waters vary greatly from year to year. As described in Section 1, NAdDW is formed in the northern Adriatic and travels to the southern Adriatic along the bathymetric slope. As it flows south this water mass becomes warmer and saltier as it mixes with MLIW south of the Palagruža Sill. The T-S properties of bottom water in the northern and central Adriatic from the VELTURO9 cruise reveal that while five stations exhibit characteristic NAdDW formation properties in the $\sim 9.0 \leq T \leq 11.35{ }^{\circ} \mathrm{C}, \sim 38.30 \leq S \leq 38.50$, and $29.35 \leq \sigma_{t} \leq 29.51$ range (see data points with $\sigma_{t} \geq 29.35$ contour outlined in green in Fig. 2b), the T-S properties of the bottom water in the individual stations are broad in range (note two stations between $\mathrm{T} 9$ and $10^{\circ}$ and three stations between $\mathrm{T} 10.5$ and $12^{\circ}$ in Fig. $2 \mathrm{~b}$ ), and water with these properties was not found outside of the north and central Adriatic. Most of the cold and fresh bottom water data collected in the three cruises, however, cluster around a point near $T=11.60^{\circ} \mathrm{C}, S=38.26$ and $\sigma_{t}=29.15$. This bottom water is warmer, fresher and therefore lighter than the climatological NAdDW and we define it as 2009 NAdDW. Since it is defined from data collected in the vicinity of the Palagruža Sill, this water is therefore a derivative of bottom water formed in the northern Adriatic in earlier months.

We speculate that the absence of climatological NAdDW water in the southern Adriatic near the Palagruža Sill is indicative of a general lack of NAdDW production in the winter of 2009 in the northern Adriatic. Small quantities of bottom water with $\sigma_{t} \geq 29.35$ before February (similar to those observed during VELTUR09) in the north were likely mixed with surrounding warmer and fresher bottom water as they traveled south, producing the observed 2009 NAdDW in March. The notion of lack of NAdDW production agrees with Book et al. (2010) who, by comparing these data to extensive surveys done in 2006, concluded that the winter of 2009 was an anomalous low year for NAdDW generation in the Adriatic. Using the seismic oceanography data collected during ADRIASEISMIC to identify the different water masses in the study area and to image NAdDW as it flowed from the continental shelf to the deep Bari Canyon, Carniel et al. (2012) also noted that neither cascading of NAdDW to the bottom of the canyon nor open-ocean deep convection processes were evident in March 2009.

Following a similar method of data clustering in T-S space to define source water masses, we can depict the other source waters found in the southern Adriatic in 2009 from Fig. 2: MLIW $\left(T=13.90{ }^{\circ} \mathrm{C}, \quad S=38.80, \quad \sigma_{t}=29.17\right), \quad \operatorname{ADW} \quad\left(T=13.10^{\circ} \mathrm{C}\right.$, $S=38.73, \sigma_{t}=29.25$ ), Adriatic Surface Water (SW; $T=13.56{ }^{\circ} \mathrm{C}$, $\left.S=38.22, \sigma_{t}=28.78\right)$, and Po River water $\left(T=8.60^{\circ} \mathrm{C} ; S=27.00\right.$, not shown). The temperature and salinity definitions for the latter source water were derived from surface data collected in a station near the Po River mouth during VELTUR09.

All in all, the data are divided among five distinct triangles (labeled 1-5 in green in Fig. 2), where each triangle endpoint represents each distinct Adriatic source water mass. Mixing between these water masses occurs along diapycnal and isopycnal mixing lines connecting the three endpoints of each distinct triangle. Further intermediate products mix along additional mixing lines, forming a cloud of points internal to each triangle, but still derived ultimately from the source waters at the triangle vertices. Based on the chosen water mass definitions, most data occur within Triangle 1, composed of MLIW, SW, and 2009 NAdDW. In both VELTUR09 and ADRIASEISMIC cruises, the collected data spanned from the GS line north of the Gargano Promontory to the Bari region, including the SAP (see Fig. 2), and therefore data points are spread across the entire T-S domain of Triangle 1 . During IMPACT09, data were collected primarily in the Bari region, 
south of the Gargano Promontory and so the T-S characteristics are concentrated near the MLIW and ADW source water masses (Triangles 1 and 2), with less influence of 2009 NAdDW or SW water masses. Further spreading of the data away from Triangles 1 and 2 for all cruises is indicative of the remote influence of LIW and Po River water sources.

Water mass fractions are computed for each CTD and MS cast following a modified version of the least-squares tracer analysis method developed by Mackas et al. (1987) and Vilibić and Orlić (2001, 2002). The method uses fractions of several tracer variables to find the mixture of source water types that best describes, in a weighted least-squares sense, the composition of the water sample (Vilibić and Orlić, 2002). For a detailed explanation of the method refer to the appendix in Vilibić and Orlić (2001).

In our analysis, we use two tracers: temperature $(T)$ and salinity $(\mathrm{S})$, so the fractions (F) of a total of three (A, B, and C) water masses: 2009 NAdDW, MLIW and SW in Triangle 1, and 2009 NAdDW, MLIW and ADW in Triangle 2 are computed

$F_{A} T_{A}+F_{B} T_{B}+F_{C} T_{C}=T_{o}$

$F_{A} S_{A}+F_{B} S_{B}+F_{C} S_{C}=S_{o}$

$F_{A}+F_{B}+F_{C}=1$

Following Vilibić and Orlić (2001), we impose the constraint (1c) and thus the problem is reduced to a system of three equations and three unknowns (FA, FB, and FC). In the analysis, the fractions of each source water mass are computed at each data point within each CTD or MS cast. By definition, for a given data point inside a triangle, the source water fraction is zero for all water masses that are not the bounding vertices of the triangle containing the data point. Thus, a particular data point can only be composed of at most three source waters by this methodology.
We acknowledge that applying this simplified methodology leads to limitations in the analysis. First, the definition of source water masses via a single $\mathrm{T}-\mathrm{S}$ point is a simplification that is especially relevant in the Adriatic Sea, where there is a large variability in source water definitions in T-S space. Second, the method is sensitive to the time period over which it is applied. Surface waters in the Adriatic are, for example, affected by a seasonal signal, so if the time period of data collection is long, determining the fraction of this source water with any certainty may be difficult.

An example of water mass division is shown in Fig. 3 using T-S curves from three individual CTD/MS casts collected during ADRIASEISMIC. The T-S data are plotted at every meter with the color scale indicating depth at each cast. Panel (a) shows a CTD cast from the GS line taken on March 5, 2009, Panel (b) shows a CTD cast from the VL line collected on March 7, 2009, and Panel(c) shows an MS cast from the Bari region acquired on March 14, 2009. In Panel (a) the data start out in Triangle 1 at the surface and then transition at deeper depths into Triangles 2 and then 5. Thus, at the surface and through most of the water column, the water mass fractions are divided between SW, MLIW, and 2009 NAdDW. Once passing into Triangle 2, the source water fraction of SW becomes zero and the fractions are divided between MLIW, 2009 NAdDW, and ADW. Finally, at the bottom of this cast the source water fraction of MLIW becomes zero and the fractions are divided between 2009 NAdDW, ADW, and NAdDW. In Panel (b) all data are in Triangle 1, so all source water fractions are divided between SW, MLIW and 2009 NAdDW. In Panel (c) data above $300 \mathrm{~m}$ have source waters divided between SW, MLIW, and 2009 NAdDW, while data below $300 \mathrm{~m}$ have source waters divided between MLIW, 2009 NAdDW, and ADW.

Despite the low production of NAdDW in the northern Adriatic in the winter of 2009, the T-S characteristics of the three casts in Fig. 3 indicate that the anomalously warmer and fresher 2009 NAdDW that was generated in the northern and central Adriatic
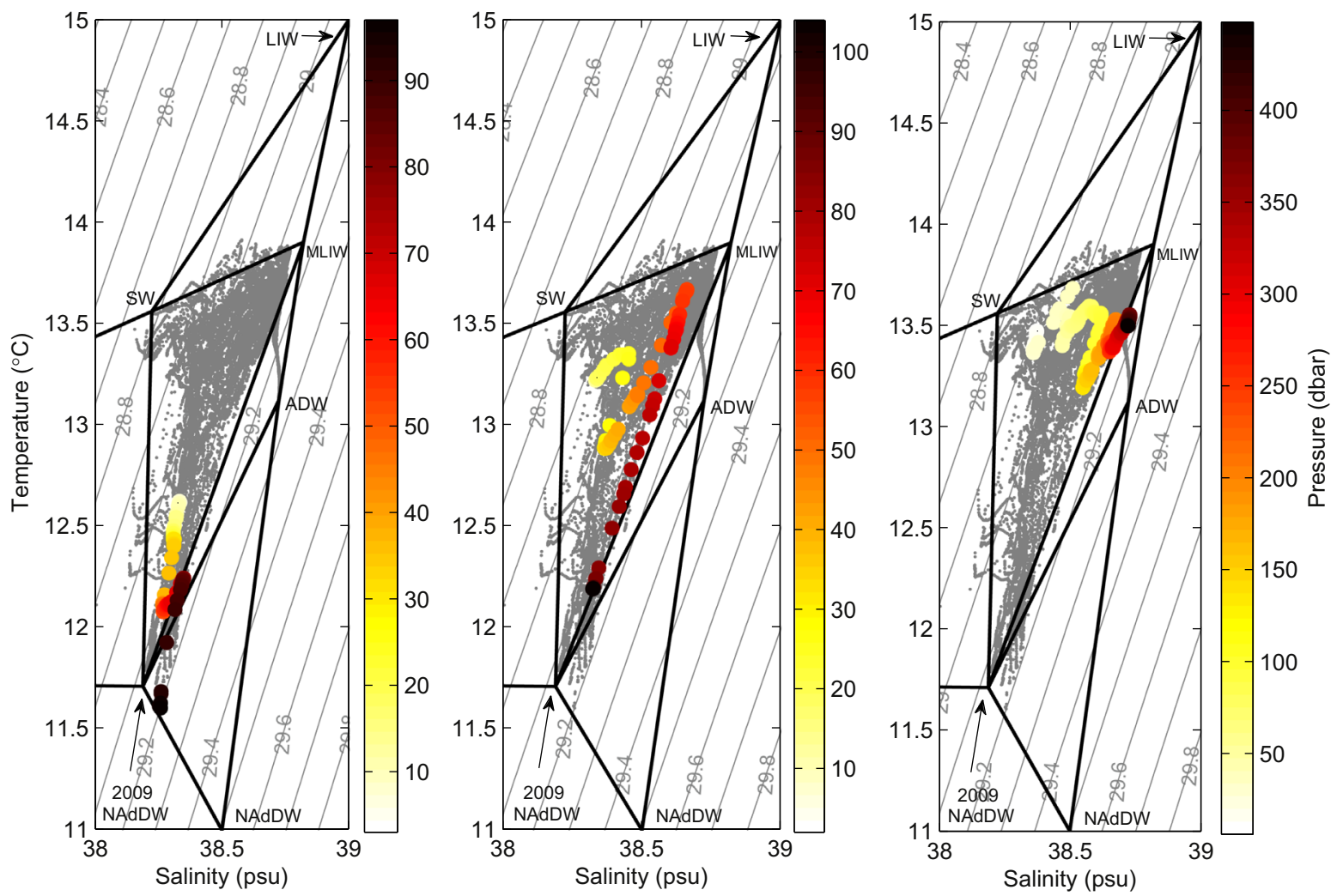

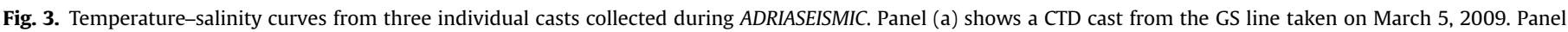

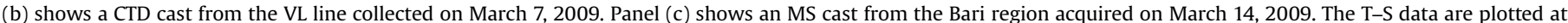
every meter with the color scale indicating depth at each cast. 
shelf was mixed with MLIW, SW and ADW as it traveled south from the Gargano to the Bari region in the early spring. The T-S curve of the GS line cast (3a) to the north of the Gargano Promontory shows a thin ( $\sim-10 \mathrm{~m}$ thick) core of primarily 2009 NAdDW water near the seafloor at $100 \mathrm{~m}$, with warmer and slightly less dense water above it. This core is absent in the T-S characteristics of the VL cast (3b), collected about one day later south of the Gargano Promontory, and suggests a greater degree of isopycnal mixing of 2009 NAdDW with incoming MLIW from the South Adriatic Pit, in addition to mixing with SW near the top of the water column. The two kinks observed on the T-S curve at about $45 \mathrm{~m}$ and $55 \mathrm{~m}$ depth are warm and cold water intrusions, respectively, and are indicative of water mass mixing and interleaving. Lastly, in the Bari region (3c), T-S characteristics of the cast performed there indicate less influence of 2009 NAdDW on water masses in the southern part of the Adriatic basin and greater influence of MLIW and ADW derived waters. The mixing and dilution of NAdDW with other Adriatic water masses as this water mass traveled south is studied in more detail in the next two sections using the results of such water mass fraction analyses, and water mass fluxes estimated by combining these results with ADCP current measurements.

\subsection{Source water flux analysis}

As described in Section 2, velocity measurements were made from two VMADCPs and from LADCP casts. VMADCP data for both the $\mathrm{WH} 300 \mathrm{kHz}$ and $0575 \mathrm{kHz}$ instruments were combined in all available CTD sections. Due to the hull location of the instrument and high noise levels in the top few meters of the water column, the WH300 kHz data were available no shallower than $11 \mathrm{~m}$ depth and reached a depth no deeper than $75 \mathrm{~m}$. OS75 kHz data reached to a depth a few meters above the seafloor at a lower resolution and were used to complete the water column velocity profiles. In order to remove data gaps that had emerged during the processing stage, a simple interpolation method was prescribed, whereby computed horizontal and vertical correlation scales were used as weights in a nearest neighbor interpolation scheme. Lastly, across-section velocities were detided using tidal solutions taken from Adriatic simulations of the Navy Coastal Ocean Model (NCOM) forced by the Oregon State University tidal databases (Martin et al., 2009).

Sections of across-section LADCP velocity data were similarly generated where available by detiding and rotating the data. However, it is important to note that no statistically significant LADCP data were collected in the top $40 \mathrm{~m}$ of the water column. All in all, the spatial resolution of VMADCP sections was higher than equivalent LADCP sections. However, except in sections in the Bari Canyon area where the VMADCP noise levels were low due to less starting and stopping of the ship for cast acquisition, we deemed the quality of the LADCP data to be higher. Therefore, we used LADCP data to compute source water fluxes in the GS and S06 lines in the Gargano Promontory area, and utilized VMADCP section data to compute fluxes in the S15 line in the Bari Canyon. Note that due to the lack of velocity data in the top $40 \mathrm{~m}$ of the water column in the Gargano Promontory region, the fluxes computed in this area were consequently underestimated for these sections. Also, it is worth noting that since fluxes were computed for partial cross-sections of the Adriatic, our source water flux estimates were all likely to be underestimated versions of the true total source water fluxes.

\subsection{The seismic oceanography method}

As the field study name indicates, part of the ADRIASEISMIC experiment consisted in collecting seismic reflectivity data in the southern Adriatic Sea via the relatively new seismic oceanography technique (Holbrook et al., 2003). This method employs lowfrequency $(10-200 \mathrm{~Hz})$ sound waves in the ocean to generate direct reflections off temperature contrasts in the water column. The reflections are then used to identify water mass boundaries on scales of meters to tens of meters (Ruddick et al., 2009; Carniel et al., 2012). With a horizontal and vertical resolution of 6-12 m, and data spanning from $\sim 50 \mathrm{~m}$ depth to the seafloor, a seismic reflectivity record is effectively a rolling snapshot of water mass structure that is ideal for identifying water column features such as eddies, fronts, and oceanic fine-scale structure. In the ADRIASEISMIC experiment, this technique was deemed particularly useful for the detection of the thin and dense NAdDW source water mass.

Large reflectors in seismic reflectivity images are evidenced by alternating dark and light bands, and indicate areas of strong vertical temperature gradients. It is important to note that an isolated water column reflectivity feature produces multiple reflectivity bands (Carniel et al., 2012). For a more detailed explanation of the seismic oceanography technique, the system used to acquire these data during ADRIASEISMIC, and interpretation of seismic reflectivity data in general, the reader is referred to Carniel et al. (2012) and references therein.

\section{Results}

\subsection{Water mass distribution in Spring 2009}

\subsubsection{NAdDW and MLIW}

Figs. 4-7 show depth-averaged source water fractions and selected section views of source water fractions for 2009 NAdDW, MLIW and SW (sections only), respectively at each station during the VELTUR09 experiment. Figs. 8-14 are comparable results from the ADRIASEISMIC field study. The solid vertical lines in the section figures indicate the location of CTD casts. Source water intrusions in the study area were successfully observed via these section plots. In the figures, source water fraction boundaries were not generally characterized by smooth transitions, but rather by alternating peaks in minima, which were indicative of the presence of such intrusions and interleaving along the sections.

During VELTUR09, the CTD cast acquired on the $35 \mathrm{~m}$ isobath in the GS line and the cast collected inshore of the $35 \mathrm{~m}$ isobath in the VL line (Figs. 4 and 5) exhibited T-S properties that were colder and fresher than water masses in Triangles 1-5 (i.e. the T-S relationships lay within the cloud of fresh and low density points representing a variation of Po River water also seen in the CTD casts acquired in the central and northern Adriatic and shown in Fig. 2b). Since these waters were outside of the five T-S triangles in Fig. 2, the source water fractions of SW, MLIW, 2009 NAdDW, NAdDW, and ADW were all undefined for these data. Furthermore, for the analysis of water mass distribution, it is important to bear in mind that the data sections in the individual field studies were for the most part not collected in chronological order, or from

Table 1

The order of data collection by transect in the VELTURO9 and ADRIASEISMIC field studies.

\begin{tabular}{ll}
\hline Transect & 2009 Date \\
\hline VELTUR09 GS line & February 28 \\
VELTUR09 SAP CTDs & February 28 \\
VELTUR09 VL line & March 1 \\
VELTUR09 Bari line & March 1-2 \\
ADRIASEISMIC GS line & March 5-6 \\
ADRIASEISMIC VL line & March 7 \\
ADRIASEISMIC S06 line & March 10 \\
ADRIASEISMIC MS VL line & March 11 \\
ADRIASEISMIC S17 line & March 14-15 \\
ADRIASEISMIC South of Bari line & March 15 \\
ADRIASEISMIC MS S15 line & March 15 \\
\hline
\end{tabular}




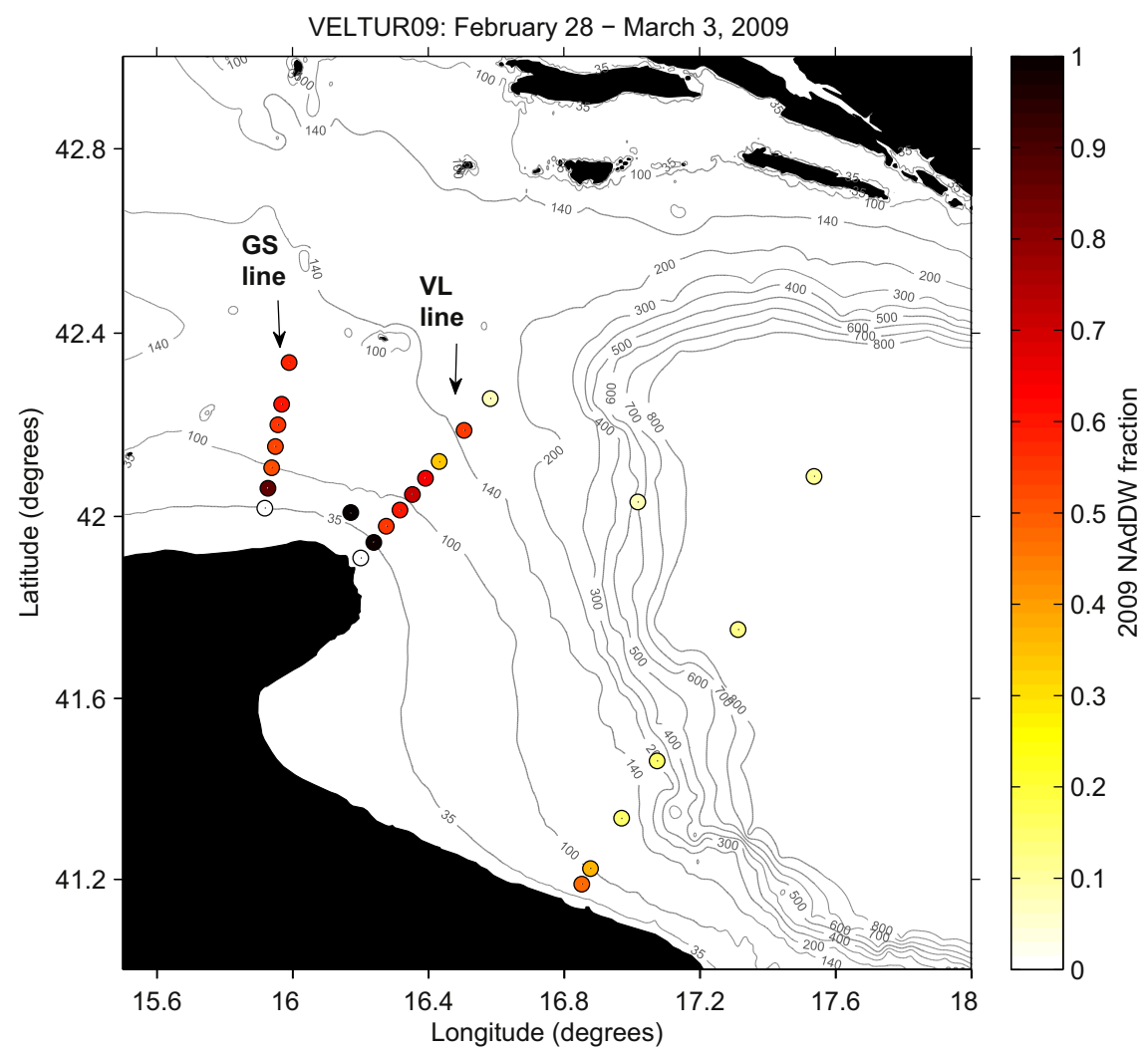

Fig. 4. Depth-averaged 2009 NAdDW source water fractions during the VELTUR09 experiment. Each dot represents the depth-averaged source water fraction (from 0 to 1 ) for each CTD station of the experiment.

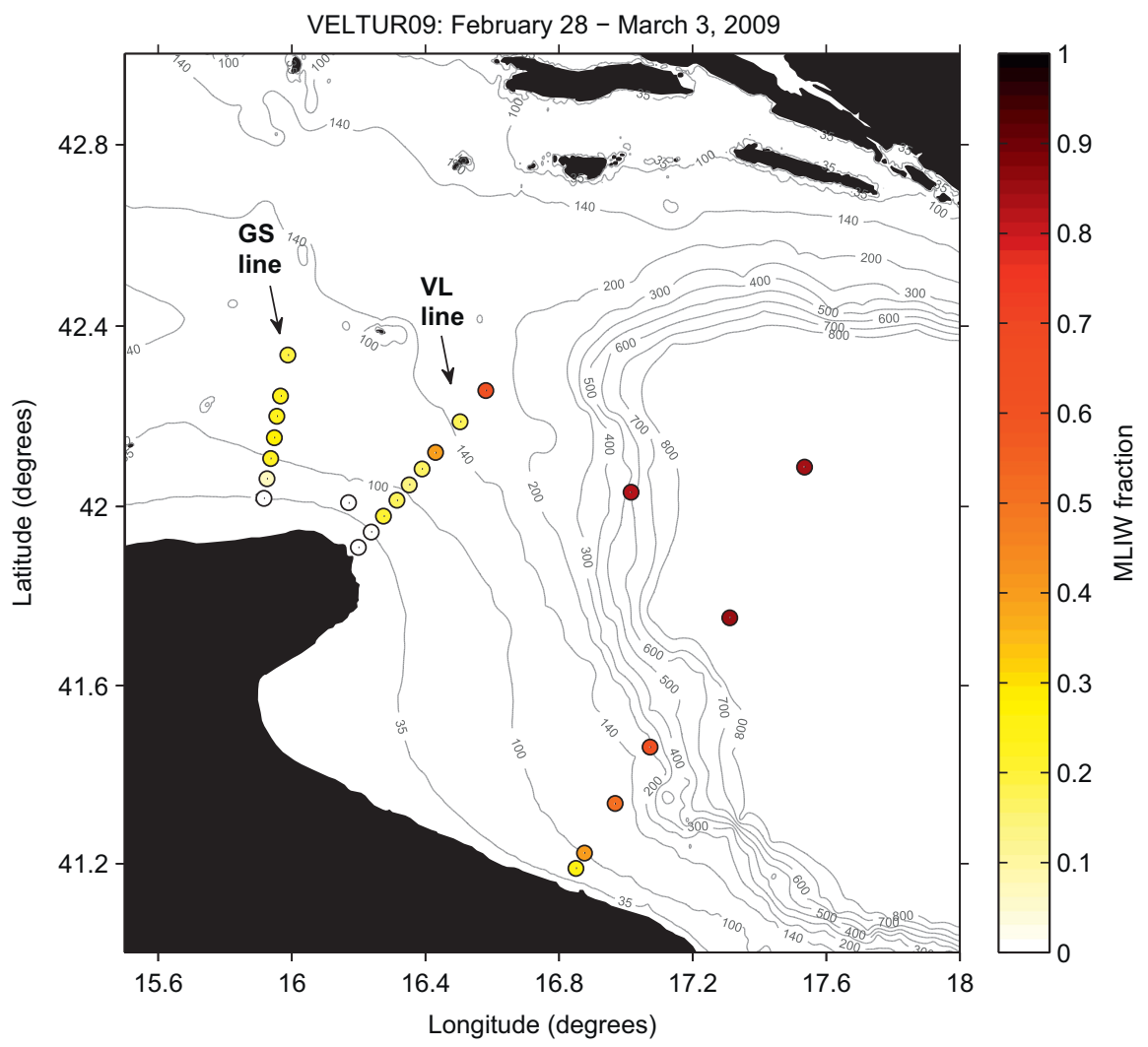

Fig. 5. As in Fig. 4, but for MLIW source water fractions during the VELTURO9 experiment. 

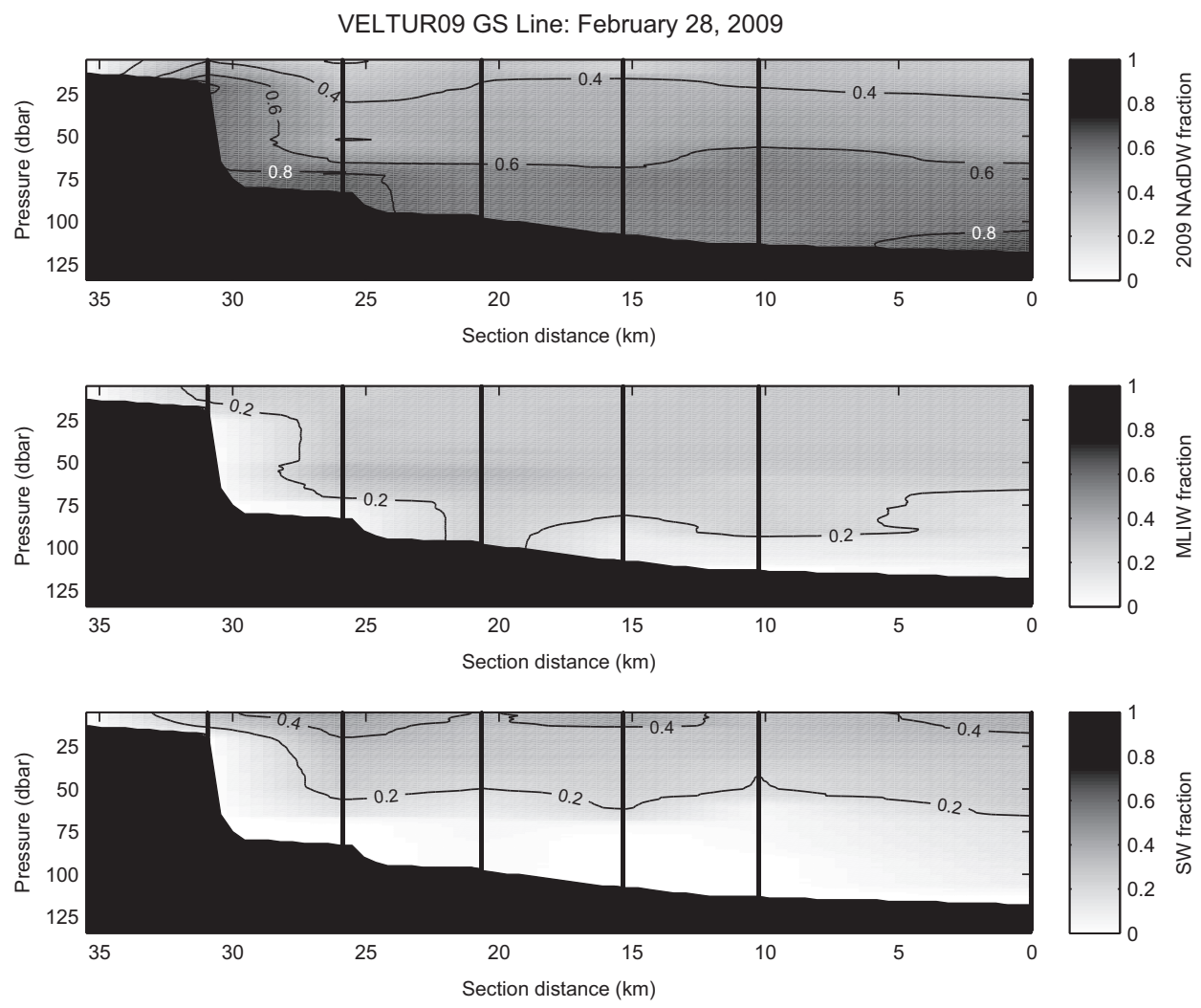

Fig. 6. Source water fractions of 2009 NAdDW (top), MLW (middle) and SW (bottom) for the GS line (February 28) during VELTUR09. The solid vertical lines indicate the along-line location of CTD casts.
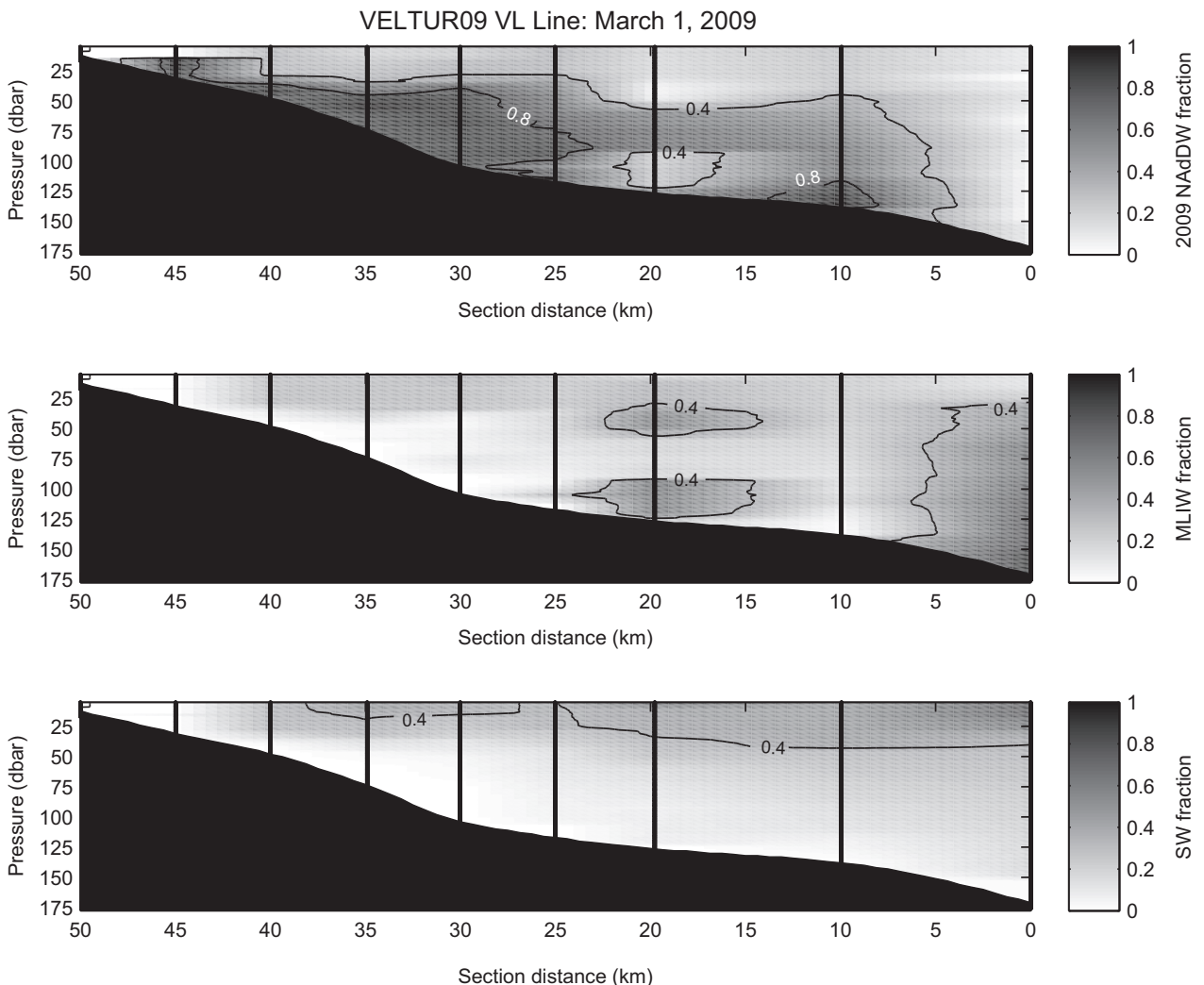

Fig. 7. As in Fig. 6, but for the VL line (March 1) during VELTUR09. 


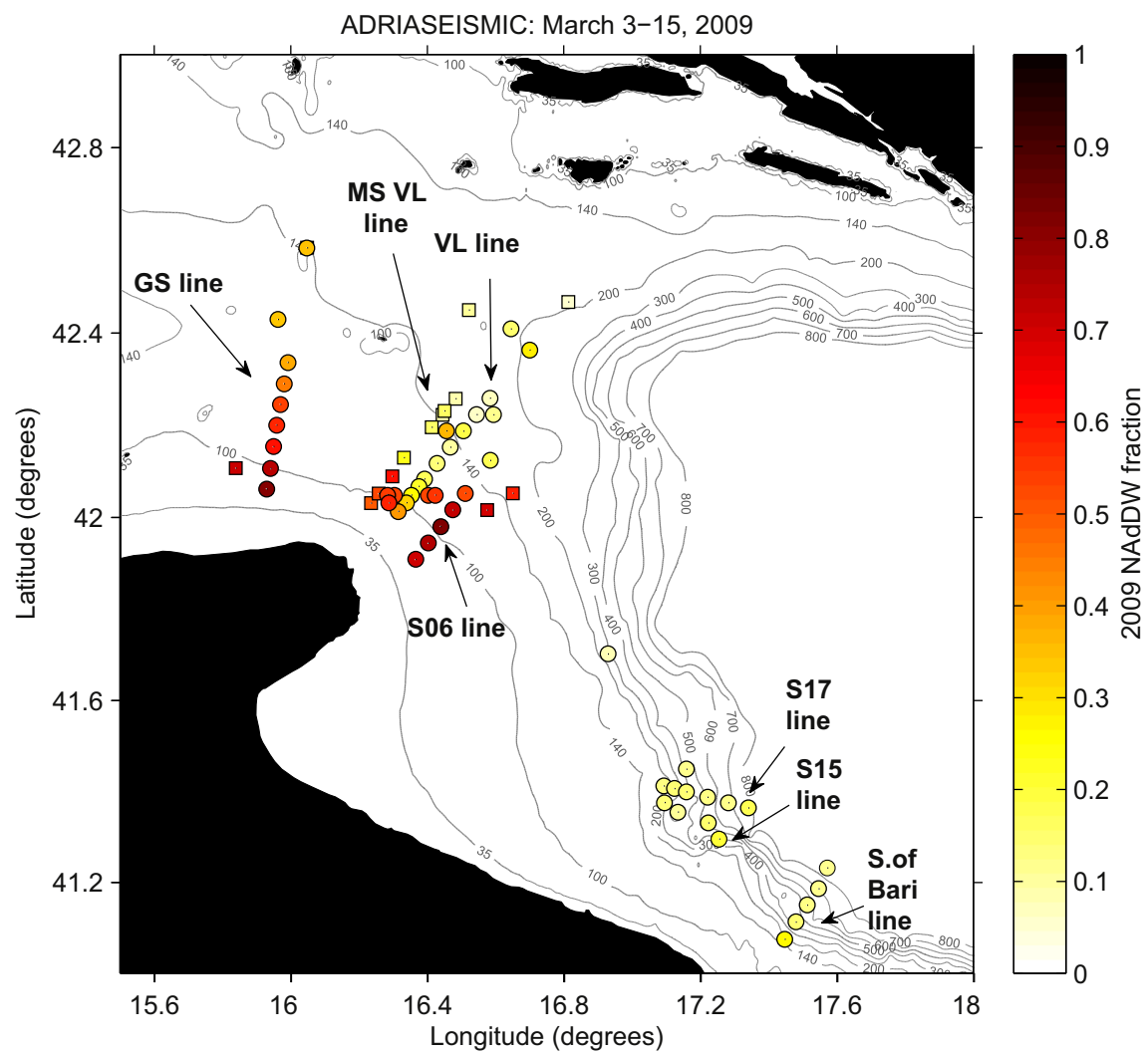

Fig. 8. Depth-averaged 2009 NAdDW source water fractions at each CTD and microstructure (MS) station during the ADRIASEISMIC experiment.

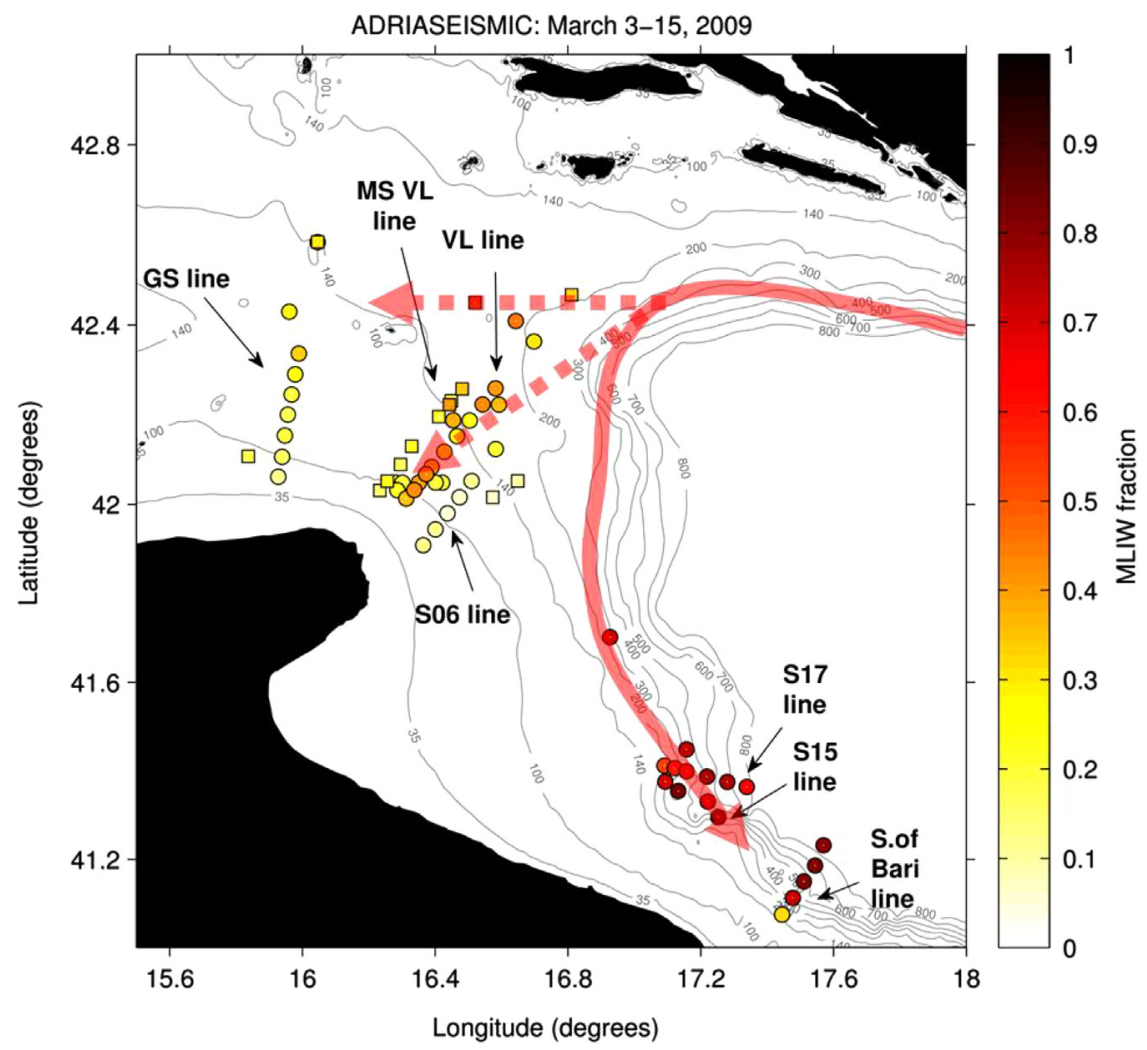

Fig. 9. As in Fig. 8, but for MLIW source water fractions. MLIW cores observed as far north as the GS line and on lines in the Gargano Promontory region suggest a splitting of MLIW pathways and MLIW intrusions towards the central Adriatic, as depicted by the dashed red arrows. (For interpretation of the references to color in this figure legend, the reader is referred to the web version of this article.) 

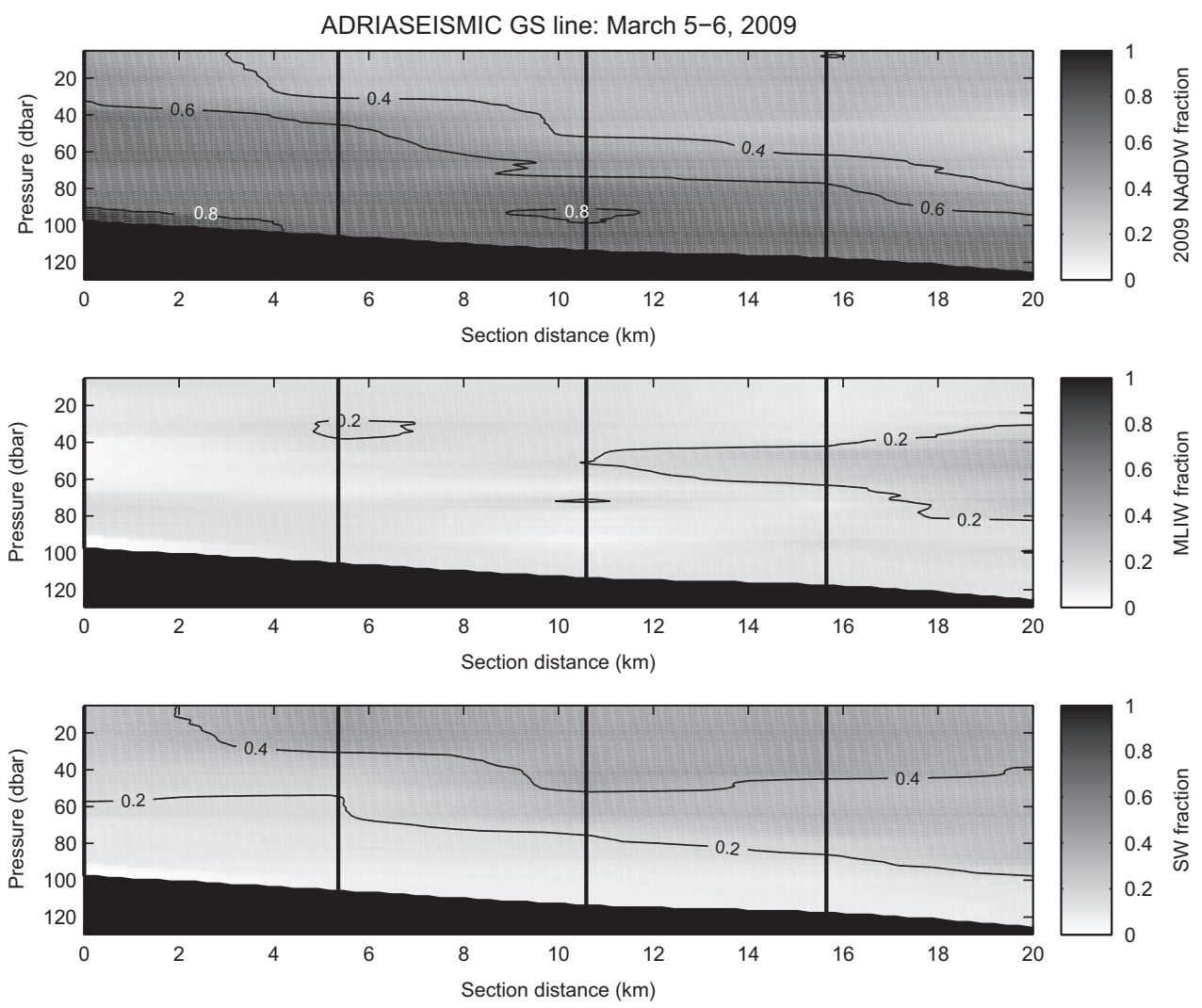

Fig. 10. As in Fig. 6, but for the ADRIASEISMIC GS line (March 5-6).
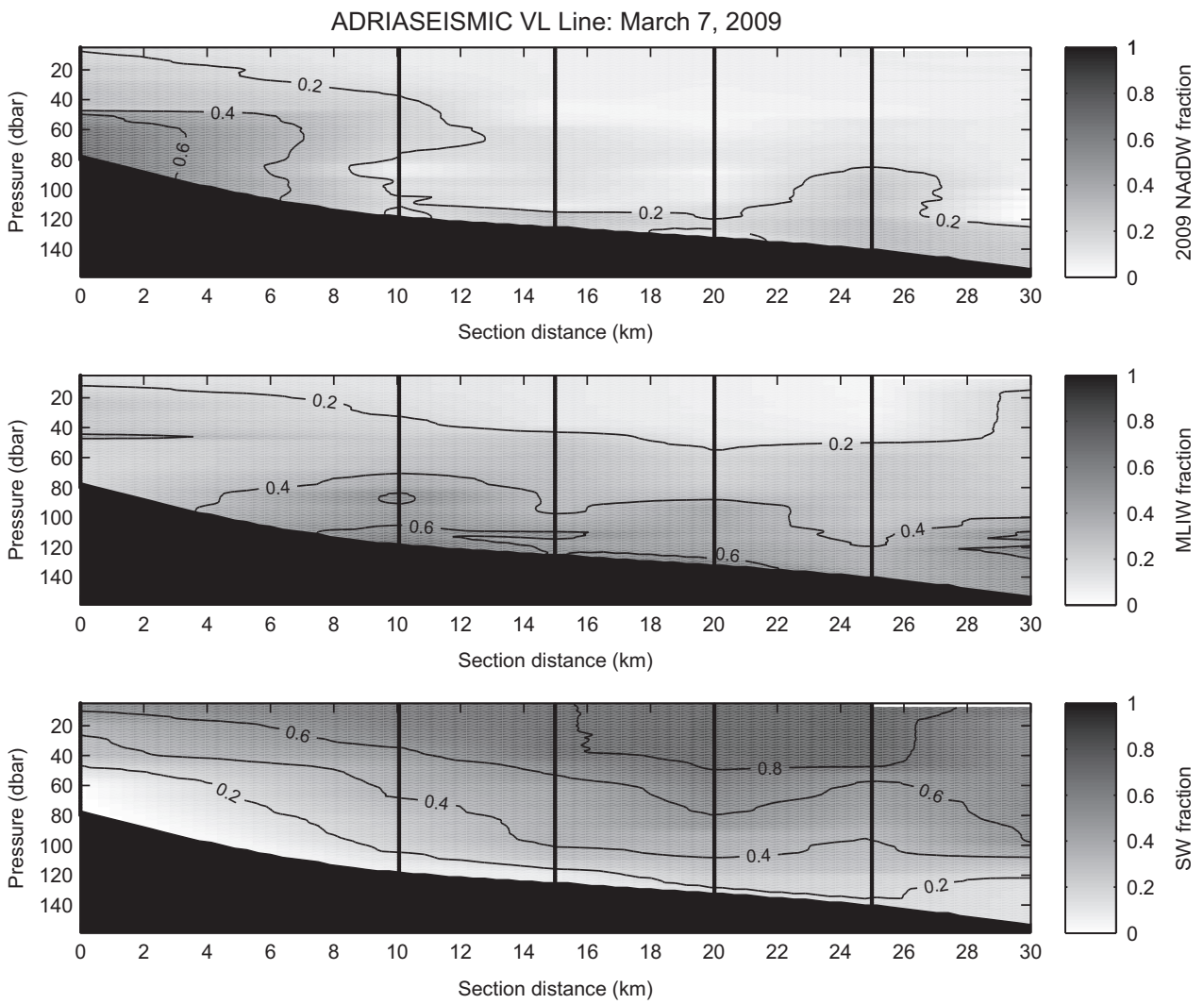

Fig. 11. As in Fig. 10, but for the VL line (March 7) during ADRIASEISMIC. 

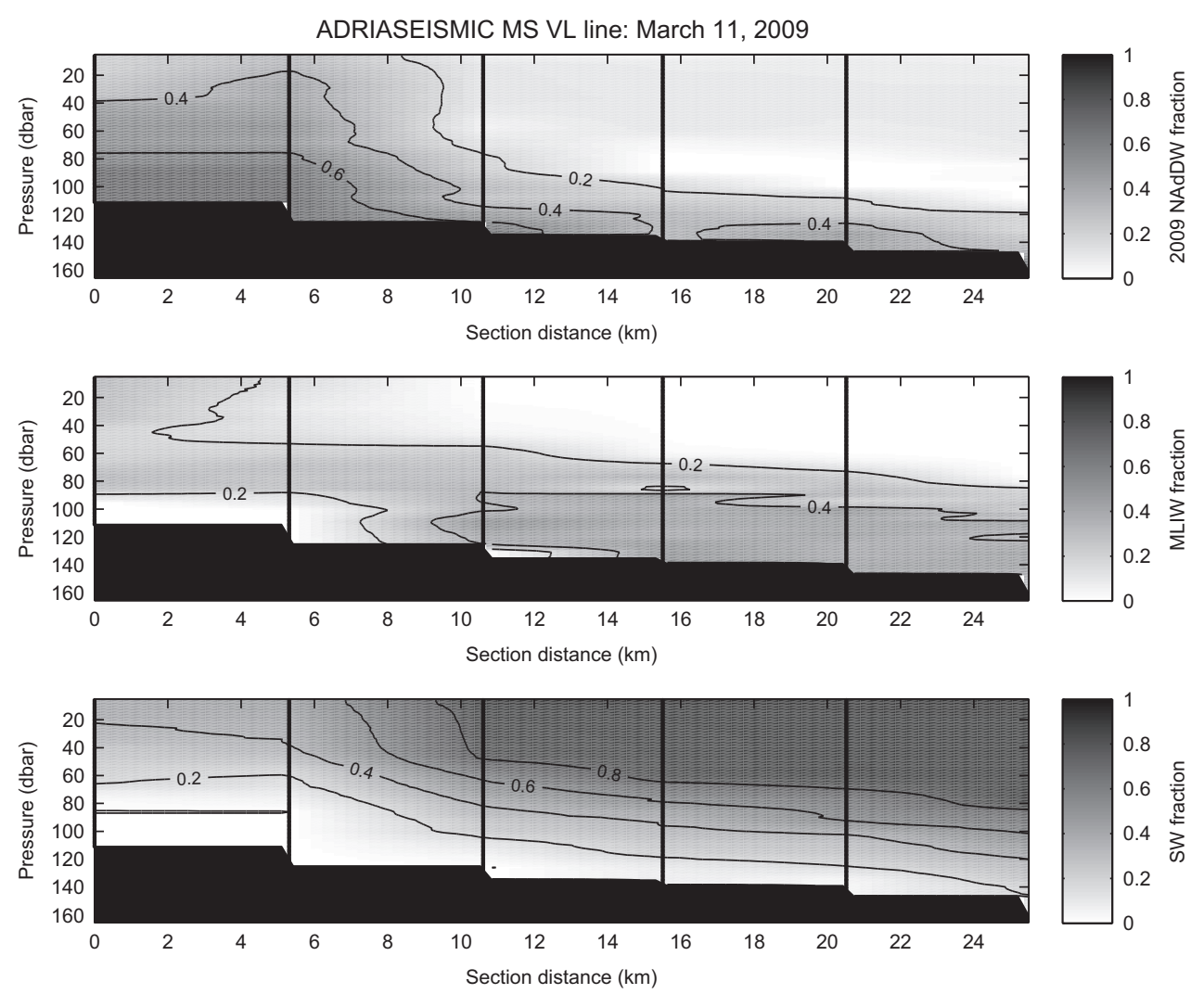

Fig. 12. As in Fig. 10, but for the MS VL line (March 11) during ADRIASEISMIC.
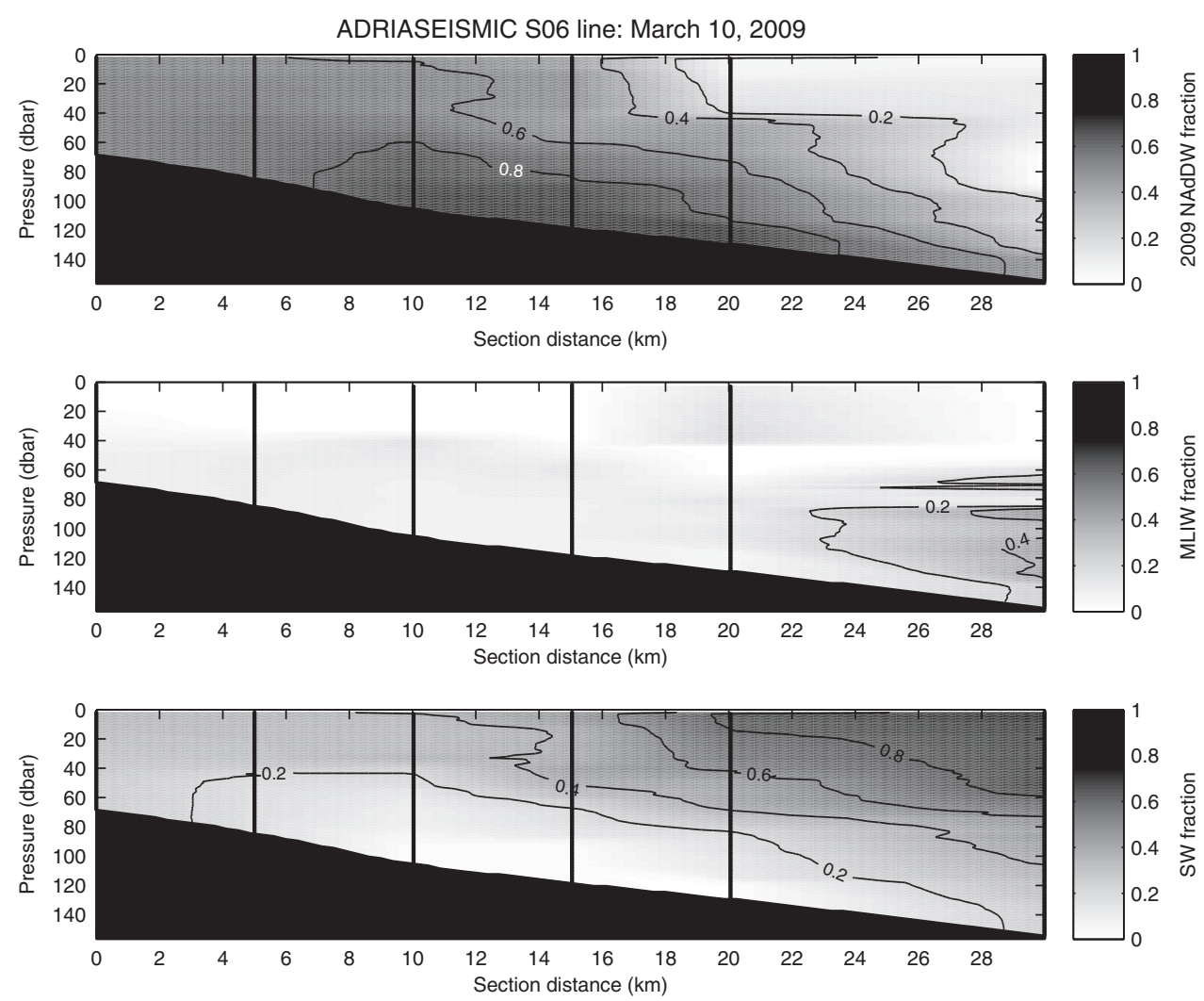

Fig. 13. As in Fig. 10, but for the S06 line (March 10) during ADRIASEISMIC.

north to south. For reference, Table 1 gives the order of data collection by transect in the VELTURO9 and ADRIASEISMIC field studies. Lastly, it should be noted that although the microstructure casts collected on the GS and VL lines (squares in Figs. 8 and 9) in the ADRIASEISMIC experiment were not collected at the same time as the CTD casts on those lines (e.g. MS cast data on the MS VL line 

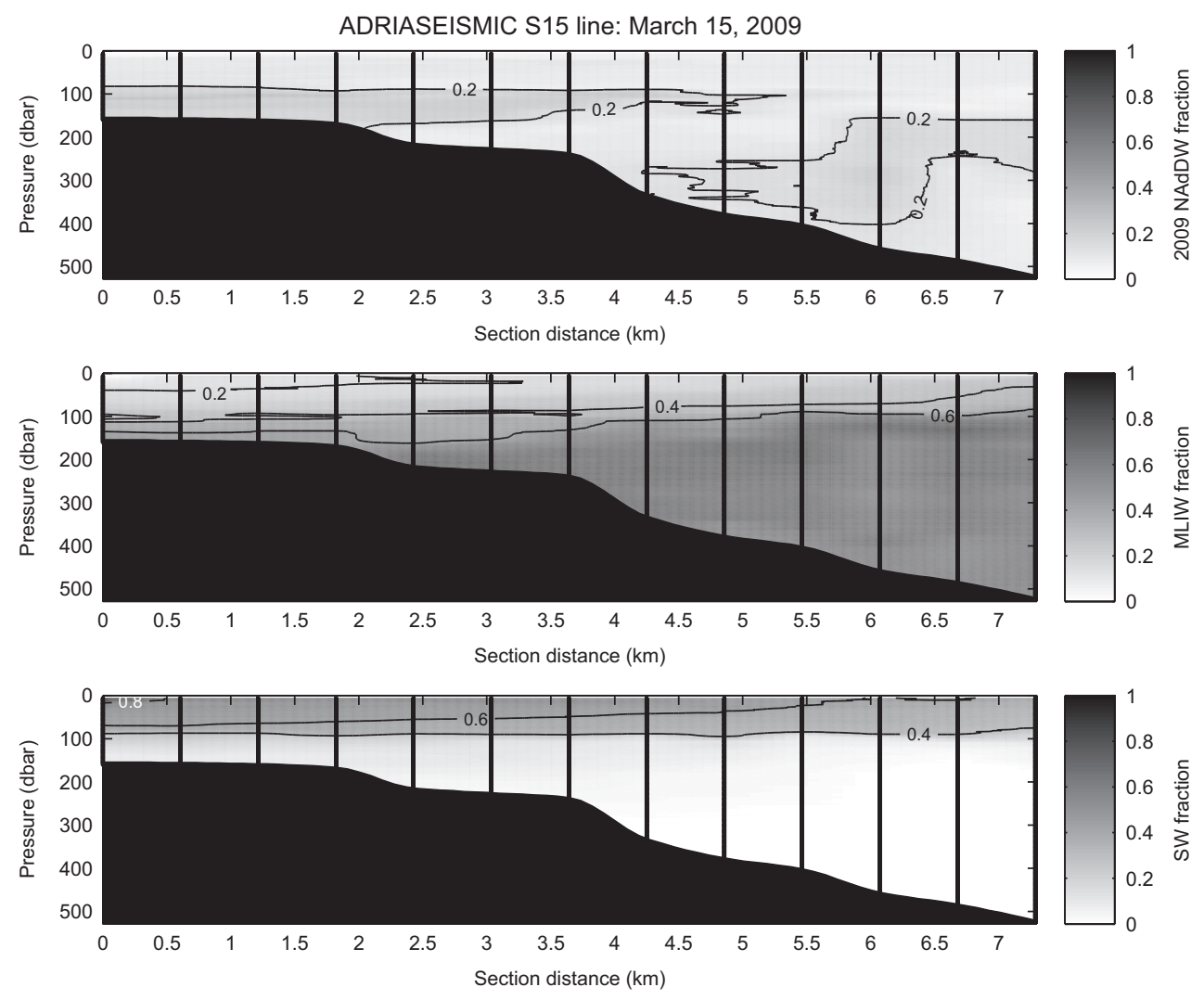

Fig. 14. As in Fig. 10, but for the S15 line (March 15) during ADRIASEISMIC.

were collected on March 11, while the CTD casts on the VL line were collected on March 7), these data were collected at the exact same location as the CTD casts (circles). For graphical clarity they were plotted slightly offset to the west of the true CTD cast locations.

As anticipated by Fig. 2, depth-averaged source water fractions for VELTURO9 and ADRIASEISMIC show that the largest 2009 NAdDW fractions (Figs. 4 and 8) occurred in the northernmost lines of the southern Adriatic (i.e. GS, VL and SO6 lines) near the Gargano Promontory region, while in all three experiments (IMPACT09 results not shown), the largest MLIW fractions resided in the Bari and South of Bari regions of the study area. The lower depth-averaged fractions of MLIW (Figs. 5 and 9) on stations on the shelf and Sill, as compared to higher fractions within the SAP, suggest that the main pathway of MLIW water was around the South Adriatic rim in agreement with past studies ((Poulain, 2001; Manca et al., 2002). Adriatic surface water (SW) fractions as defined in this study were found to be larger in the Palagruža Sill region (up to 80\%, Figs. 11-13), than in the Bari and north of the Gargano Promontory regions (Figs. 6, 10 and 14), where largest SW fractions were mostly in the $40-60 \%$ range. In the Gargano Promontory and northern regions, this source water mass occupied, in various fractions, most of the water column, while in the Bari region it resided in the top $100 \mathrm{~m}$ (Fig. 14).

The core of 2009 NAdDW was observed at various strengths and extents near Gargano, sometimes stronger and larger (Figs. 7 and 13) and sometimes weaker and smaller (Figs. 6, 1012). In the two transects of the GS line, 2009 NAdDW was found concentrated in a dense thin layer (5-10 m) near the seafloor inshore of the $100 \mathrm{~m}$ isobath (Figs. 6 and 10). A clear example of the variation of 2009 NAdDW is the observed weak 2009 NAdDW core $(60 \%)$ in the VL line, which reached to the $90 \mathrm{~m}$ isobath on
March 7 (Fig. 11) and extended to the $120 \mathrm{~m}$ isobath 4 days later, on March 11 (Fig. 12). The higher fractions of 2009 NAdDW at the VELTUR09 VL line (March 1, Fig. 7) than the upstream GS line (February 28, Fig. 6), in addition to the weaker 2009 NAdDW core observed in between sections with stronger cores in ADRIASEISMIC (Fig. 8), show that the 2009 NAdDW vein was not a continuous steady stream flowing towards the southeast. In the Gargano Promontory and northern regions, 2009 NAdDW was generally present at fractions $>50 \%$ in the zone between $35 \mathrm{~m}$ and $140 \mathrm{~m}$ isobaths (Figs. 6, 7, and 10-13) with the strongest core often located in the vicinity of the $100 \mathrm{~m}$ isobath. In the Bari region and southward, remnants of 2009 NAdDW were still clearly present (Fig. 14), but the fractions were much lower (on the order of $20 \%$ ) due to mixing and dilution of the core with MLIW and SW.

As previously noted, large fractions of MLIW observed in the Bari region, as opposed to the Gargano region, indicated that the main pathway for this water was around the steep contours of the South Adriatic rim. However, diluted MLIW was observed over the Sill (Figs. 5, 6, 9, 10). The offshore core of MLIW was observed as far north as the GS line during ADRIASEISMIC (Fig. 10) and observations on other lines in the Gargano Promontory region (Figs. 5 and 9) suggests a splitting of MLIW pathways and intrusions of MLIW towards the central Adriatic. We speculate that one of the MLIW intrusion pathways may have been to the north of the S06 line, reaching the offshore edge of this line during ADRIASEISMIC, and may have contributed to a dilution of 2009 NAdDW observed on the VL line (March 7 and March 11) to the north. The northward pathway of an MLIW intrusion is perhaps evidenced in Figs. 12 and 13, where the extent of a weak (40\%) MLIW core increases towards shallower depths from the S06 line (March 10) to the MS VL line (March 11) in one day. Interaction of the strong 2009 NAdDW vein and intruding MLIW core water was 
directly observed in the VELTUR09 VL line near section distance $20 \mathrm{~km}$, offshore of the $100 \mathrm{~m}$ isobath (Fig. 7).

\subsection{2. $A D W$}

The presence of ADW in the Spring of 2009 can be observed in $\mathrm{T}-\mathrm{S}$ space (Triangle 2 ) in Fig. 2 . The saltiness of ADW compared to other Adriatic water masses is heavily influenced by MLIW. This water mass lies on a mixing line between MLIW and NAdDW and a number of works have suggested that there is some influence from NAdDW in its properties (Gačić et al., 2001, Chapter 1: overview). However, ADW also could be formed by cooling and deep convection (Zore-Armanda, 1974) of MLIW mixed with a slight contribution from SW, as could be illustrated by drawing an imaginary vertical line upward from ADW on the T-S diagram of Fig. 2. Since there are no data scattered along the 2009 NAdDW to ADW leg of Triangle 2, nor along the MLIW to ADW leg, there is no evidence that these were active mixing pathways during the spring of 2009.

The ADW T-S curve in Fig. 2 is composed of data points collected in all three experiments within and in the vicinity of the SAP. Since ADW is a deep water mass, its presence was evident only in casts deeper than $300 \mathrm{~m}$, but significant ADW water column fractions (of $40 \%$ and higher) did not occur any shallower than $800 \mathrm{~m}$. Since the deepest areas of the SAP are located in the center of the pit, the largest source water fractions of ADW were found in the two VELTUR09 CTD casts and the single IMPACT09 CTD cast collected there (black triangles and blue diamond, respectively in Fig. 1). Unlike the cloud of data points in Triangle 1, the data for Triangle 2 collapse into a very limited set along a particular curve. Thus for Triangle 2 we observe the final product water masses rather than a mixing or formation process that was ongoing at the time of these surveys.

Fig. 15 shows the resulting MLIW and ADW water column source water fractions for the IMPACT09 CTD cast in the SAP. For clarity and interpretation, a zoomed version of the cast in T-S space is included as a subset of the figure. This cast is representative of MLIW and ADW structure in the SAP observed in all three experiments. In all casts where ADW fractions were significant, MLIW and ADW presented a symmetric structure in terms of source water fraction. As evidenced by the second kink in the T-S subset, the two water masses crossed one another anywhere from $800 \mathrm{~m}$ to $850 \mathrm{~m}$, and at the crossing, the fraction of each water mass was around 45\% (at this depth 2009 NAdDW occupied the remaining $10 \%$ of the water mass distribution). The surface water of this cast was made up of mostly MLIW source water fraction (79\%), which is an indication of how homogenized the upper water was during this measurement, since MLIW is actually an intermediate water mass. The largest MLIW fraction (about 85\%) was found at about $400 \mathrm{~m}$ (first T-S kink within Triangle 1), at which point its fraction started decreasing. Just below $600 \mathrm{~m}$, where the data points move into Triangle 2, the fraction of ADW increased progressively from $0 \%$ to about $95 \%$ at $1200 \mathrm{~m}$ depth. The T-S profile has two slight bends forming a salinity minimum near $750 \mathrm{~m}$ depth and a weak salinity maximum near $1000 \mathrm{~m}$ depth. This suggests that a freshwater mass had some influence at $\sim 750 \mathrm{~m}$ depth and near the bottom. 2009 NAdDW and NAdDW

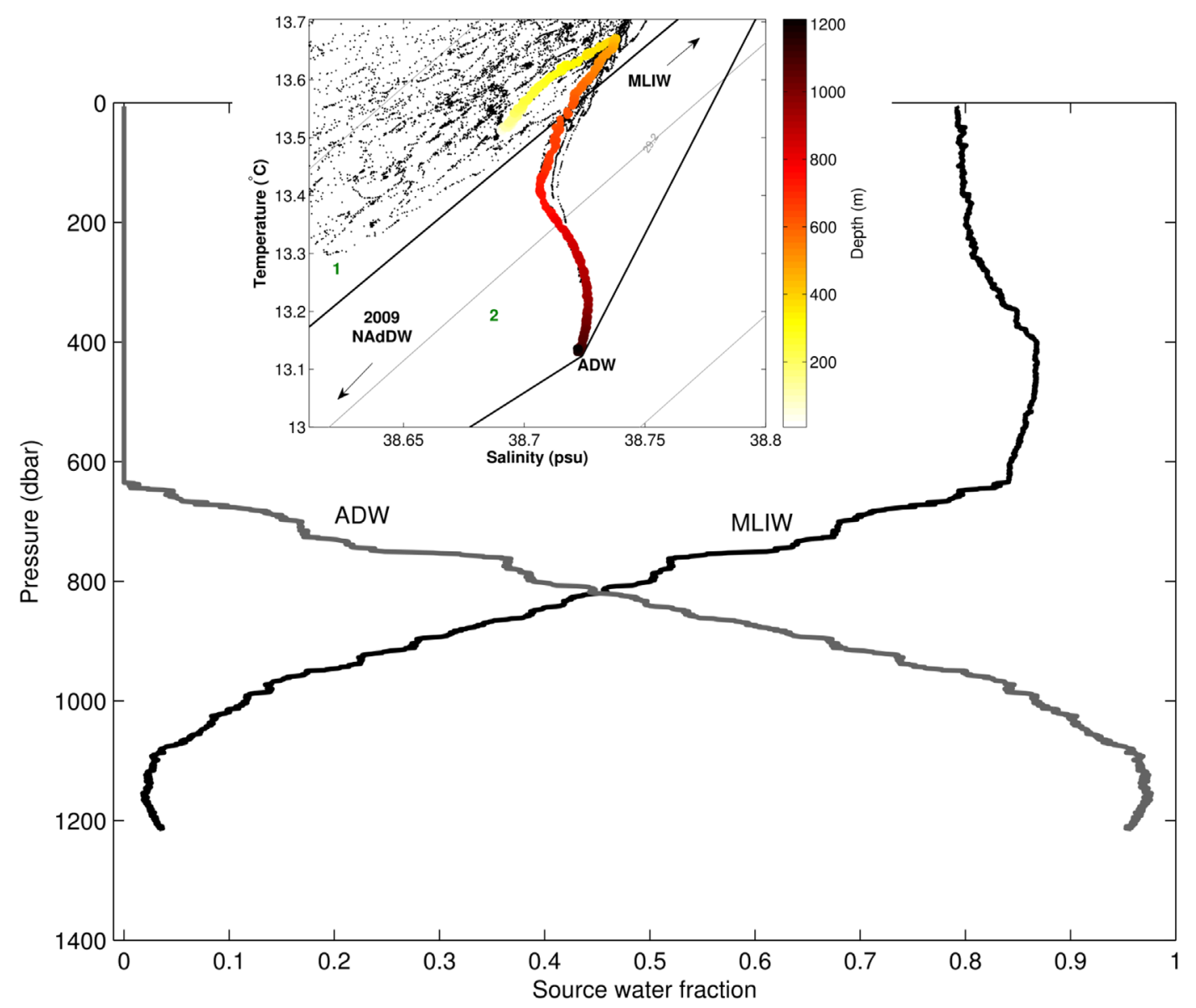

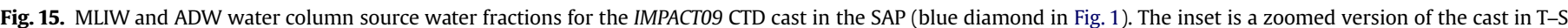

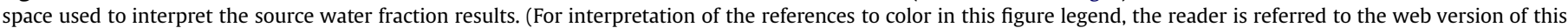
article.) 
from previous years could be responsible for both. An already mixed combination of NAdDW and MLIW of moderate density extending off the shelf at the shallower depth level, and a less mixed NAdDW descending directly down the slope or canyon systems (Vilibić and Supić, 2005; Turchetto et al., 2007) could have produced such freshening in the curvature in T-S space. An example of the former process is shown in Carniel et al. (2012), although it is to a shallower depth level. In 2006 some profiles in the SAP were observed to have a cold and fresh intrusive like minimum at 700-800 m depth near the outflow of the Bari Canyon (Book et al., 2010). As discussed by Vilibić and Šantić (2008), this process could alternatively be a sign of a past deep convection event bringing fresh surface water down to 600-800 m depth.

\subsection{Source water fluxes in March 2009 during ADRIASEISMIC}

In order to evaluate the transport and direction of travel of 2009 NAdDW and MLIW water masses in the study area, fluxes for these two source waters were estimated by combining ADCP measurements with the computed source water fractions. The overall transport of source waters was therefore revealed to be independent of the mixing and dilution processes taking place. Since velocity measurements were only available for the ADRIASEISMIC experiment, only fluxes during the March 3-15 period were estimated. The transport analysis was focused on the GS, S06 and S15 lines. For the GS and SO6 lines, a cell size of $300 \mathrm{~m}$ in the horizontal and $1 \mathrm{~m}$ in the vertical was used to compute transport, while for the S15 line a cell size of $100 \mathrm{~m}$ in the horizontal and $1 \mathrm{~m}$ in the vertical was employed.

Prior to analyzing flux results, we evaluated the general speed and direction of the currents in the study area. Fig. 16 shows depth-averaged and detided currents obtained from LADCP and VMADCP data at various times during ADRIASEISMIC. Insets (a), (b) and (c) are zooms of the currents at the GS (March 5-6), S06 (March 10) and MS S15 (March 15) lines, respectively. Velocity data for these lines are used in the next section to compute acrossline (GS and S06) and along-line (MS S15) source water fraction fluxes. In the vicinity of the Palagruža Sill (GS line), the flow closest to shore was, as expected, toward the southeast and had a magnitude of about $\sim 13 \mathrm{~cm} / \mathrm{s}$; however, further offshore it reversed towards the northwest with a maximum magnitude of $\sim 20 \mathrm{~cm} / \mathrm{s}$. South of the Sill, the currents near line S06 and north of it reveal a submesoscale cyclonic eddy $(\sim 10 \mathrm{~km}$ in diameter $)$ directly incorporated in the circulation. Maximum speeds within the 506 line were $20 \mathrm{~cm} / \mathrm{s}$, while current speeds reached $25 \mathrm{~cm} / \mathrm{s}$ north of this line on March 11 (i.e. on the MS VL line). South of S06, in between the Gargano Promontory and Bari, currents reached a maximum of $25-30 \mathrm{~cm} / \mathrm{s}$ and generally had a south-southeast direction. Current reversals observed on the VMADCP March 13 transect indicated the presence of other eddies in the study area. In the South Adriatic rim region near Bari, the flow was generally smaller in magnitude, reaching maximum velocities of $\sim 15 \mathrm{~cm} / \mathrm{s}$. On the S15 line (see inset (c)), the depth-averaged across-canyon flow (towards the Italian coast) was $\sim 10 \mathrm{~cm} / \mathrm{s}$, while the depthaveraged along-canyon flow accelerated to maximum speeds of $\sim 13 \mathrm{~cm} / \mathrm{s}$.

Figs. 17 and 18 show the calculated 2009 NAdDW and MLIW across-section fluxes (in Sv) for the GS and S06 lines, respectively. Positive values indicate fluxes towards the northwest and negative values fluxes towards the southeast. The solid vertical lines denote the locations of the LADCP casts at each section. In the vicinity of the Palagruža Sill (GS line), the flow closest to shore was, as expected and as described in Fig. 16, towards the southeast, however, further offshore it reversed towards the northwest. The total flux of 2009 NAdDW for the southeastward flowing portion of the section was estimated to be $-0.01 \mathrm{~Sv}$, while the northwestward flowing portion of the flow was estimated to be $0.05 \mathrm{~Sv}$. Therefore the total mean 2009 NAdDW flux in the GS line was about $0.04 \mathrm{~Sv}$ and towards the northwest. It should be noted that since no velocity data was available inshore of $100 \mathrm{~m}$ during our sampling, fluxes in these shallower regions could not be estimated. Figs. 4 and 8 in Section 4.1.1, however, show that the 2009 NAdDW vein flowed inshore of the $100 \mathrm{~m}$ isobath in a southeastward direction, which would act to reduce or eliminate the net northwest flux occurring offshore. Similar to the 2009 NAdDW flux, the total mean MLIW flux in the GS line was in the

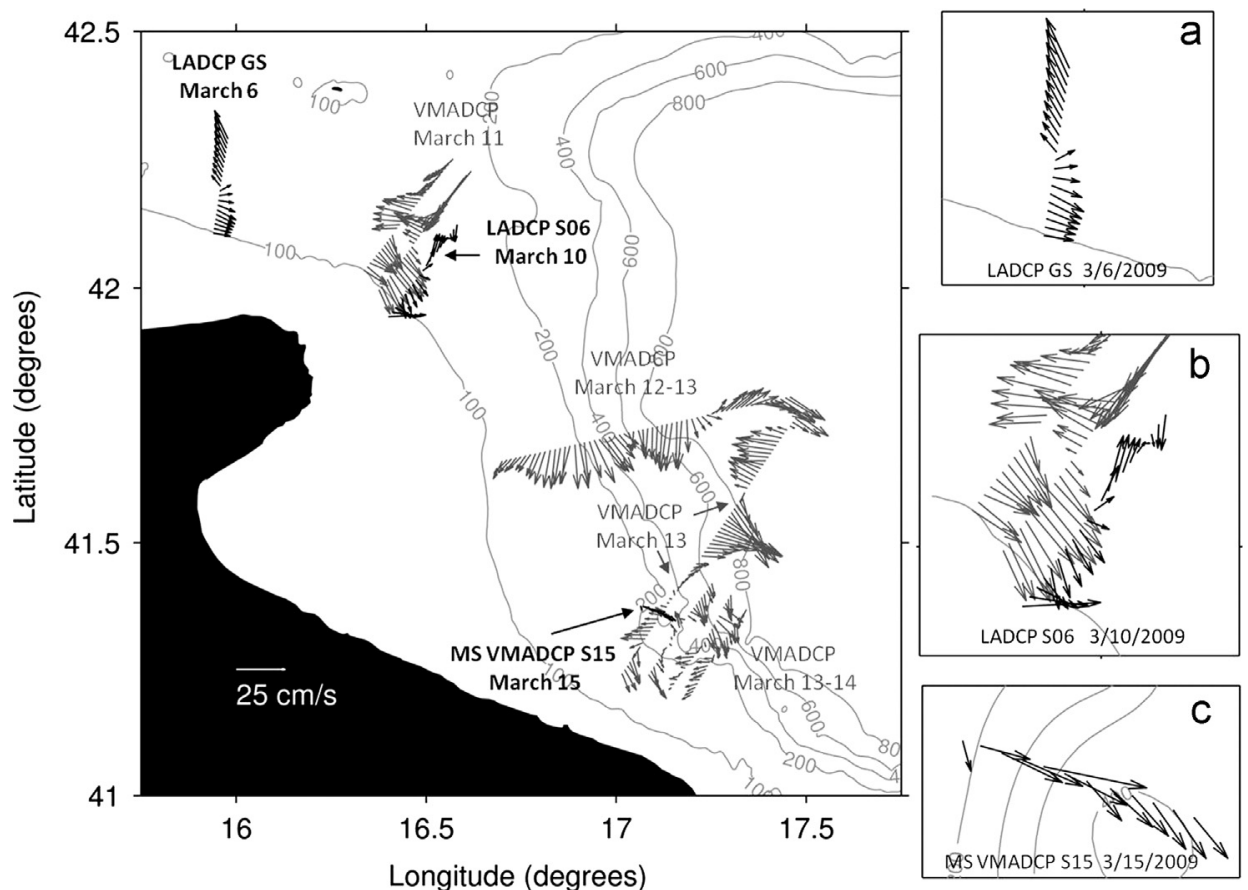

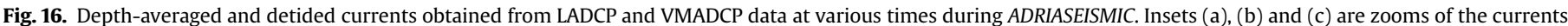
at the GS (March 5-6), S06 (March 10) and MS S15 (March 15) lines, respectively. The presence of a submesocale eddy is evident near the S06 transect. 

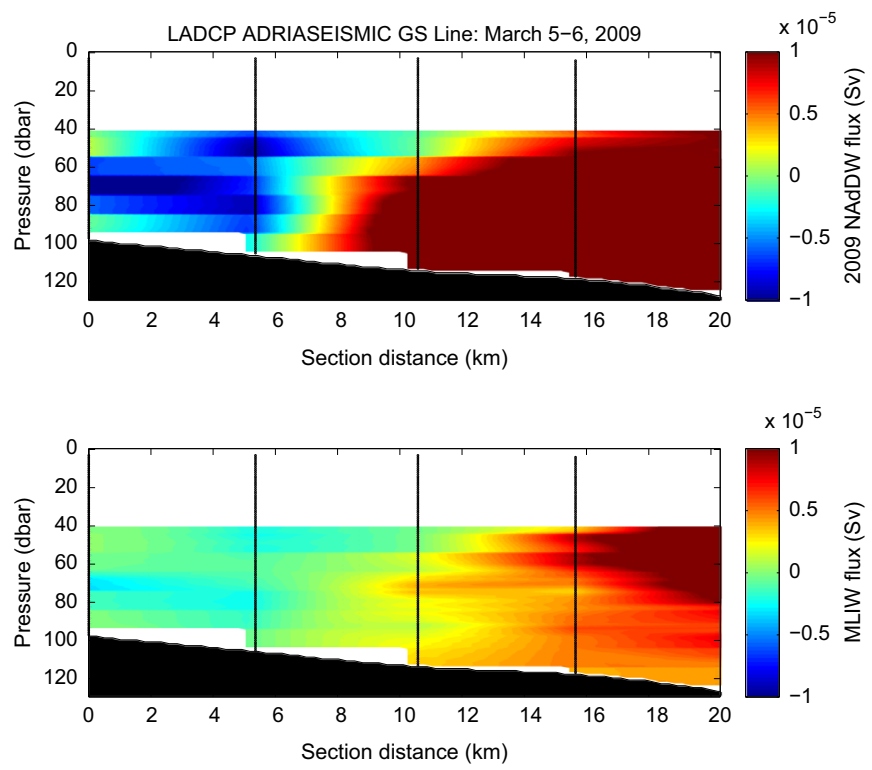

Fig. 17. Calculated 2009 NAdDW and MLIW across-section flux (in Sv) for the GS line (March 5-6) during the ADRIASEISMIC experiment. Positive values indicate fluxes towards the northwest and negative values fluxes towards the southeast. The solid vertical lines denote the locations of the LADCP casts. Note that the absence of data above $40 \mathrm{~m}$ depth is due to the lack of statistically significant LADCP data there.
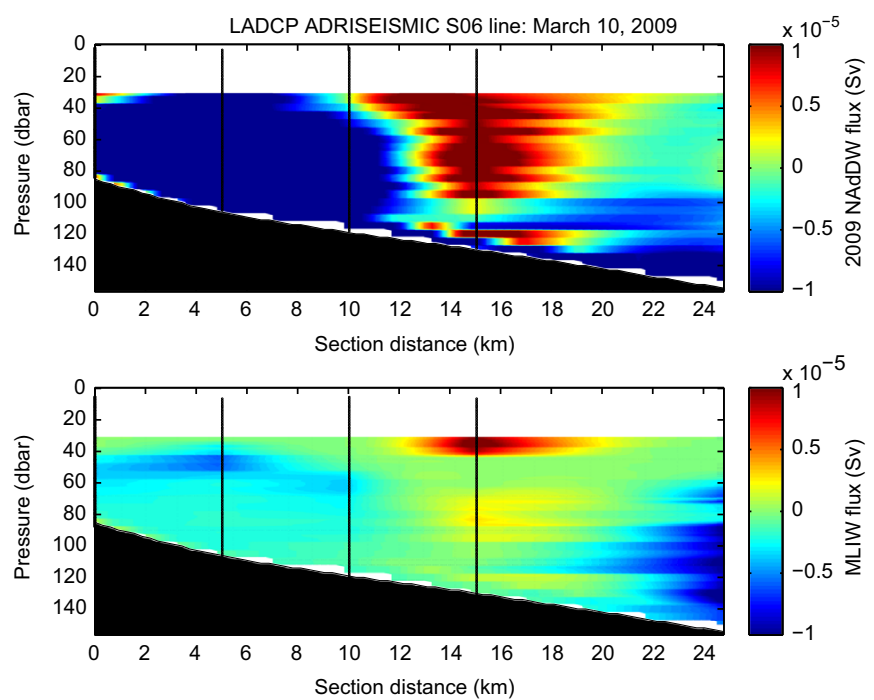

Fig. 18. As in Fig. 17, but for the SO6 line (March 10) during the ADRIASEISMIC experiment. Note that the absence of data above $\sim 35 \mathrm{~m}$ depth is due to the lack of accurate velocity data there.

northwestward direction with a magnitude of about $0.02 \mathrm{~Sv}$. This result implies that the MLIW intrusion reaching this northern section, as revealed in the source water fraction analysis, was actually transported even further north towards the central Adriatic.

South of the Palagruža Sill, on the S06 line, the observed average flow of 2009 NAdDW was directed to the southeast and produced a transport of $-0.05 \mathrm{~Sv}$ (Fig. 18). The flux was negative everywhere, except in the offshore rim of the eddy, which was transporting 2009 NAdDW waters back to the northwest. This result clearly shows that NAdDW can be absorbed and circulated in the coastal eddies that are common in this region (Burrage et al., 2009). The observed section average MLIW flux ( $-0.02 \mathrm{~Sv})$ was in the same direction as the 2009 NAdDW flux for this section, but structured very differently. MLIW fractions were significant only offshore and to a lesser degree above the 2009 NAdDW core (Fig. 13), and therefore MLIW was being circulated by the eddy only in particular depth bands. The eddy occupied roughly the upper $100 \mathrm{~m}$ of the water column and below that depth the flow was towards the southeast and transported a mixture of NAdDW and MLIW in that direction. Eddies of this kind are certainly one possible mechanism for generating MLIW intrusions towards the northwest.

For the S15 section running along the main passage of the Bari Canyon, we considered the along-section fluxes rather than across-section fluxes due to the natural orientation of the flow being aligned with the canyon walls. This analysis showed that due to increasing velocity down the canyon, both the 2009 NAdDW and MLIW transports were directed down-slope (Fig. 19) and the transport of the diluted 2009 NAdDW water mass doubled from the top $\left(1 \times 10^{-3} \mathrm{~Sv}\right)$ to the bottom of the canyon $\left(2 \times 10^{-3} \mathrm{~Sv}\right)$. The MLW transport was an order of magnitude larger than 2009 NAdDW transport, and increased from $\sim 2 \times$ $10^{-3} \mathrm{~Sv}$ at the top to $0.02 \mathrm{~Sv}$ at the bottom of the canyon. It is important to point out that even though the total mean alongsection flux of 2009 NAdDW down the Bari Canyon (S15) was at least an order of magnitude smaller than the cross-section flux in line S06 near Gargano, 2009 NAdDW was nonetheless observed traveling down the canyon in a low NAdDW production year.

\subsection{Intrusion analysis using ADRIASEISMIC seismic data}

Fig. 20 shows the seismic field (in grayscale) collected along the MS VL line, with the NAdDW (top) and MLIW (bottom) source water fraction fields for that transect (computed from MS data and displayed in Fig. 12) superimposed in semi-transparent color. When interpreting the figure, note that even though both the seismic and MS data were collected on March 11, the seismic data were acquired a few hours prior to the MS casts (vertical black lines in the figure). In addition, the horizontal resolution of the seismic data (order 6-12 m) notably far exceeded that of the MS cast data (order $5 \mathrm{~km}$ ), so that the interpolation of the MS data could have led to artificial artifacts in the source water fraction fields. The lack of seismic data at the bottom is due to a mask applied to the data to eliminate potential near bottom artifacts (Carniel et al., 2012). This composite figure is similar to Fig. 5 in Carniel et al. (2012), which displays the same seismic data, but is superimposed instead with a simultaneous temperature field obtained from eXpendable BathyThermograph (XBT) data. As discussed in Section 3.1 of the present paper, the source water fraction fields are computed by using both temperature and salinity, and should better represent the water mass boundaries in the water column than the temperature field alone.

There is generally good qualitative agreement between the source water fraction field and the seismic reflectivity data. The upper boundary of a diluted MLIW intrusion (40\%) near $10 \mathrm{~km}$ (Fig. 20, bottom panel) coincides with the strong dark reflector observed in that area, and is related to the upper boundary of a warm and salty tongue. This intrusion of MLIW occurs just a few kilometers away from NAdDW influenced waters, as is evidenced by the diluted (60\%) NAdDW core observed from 0 to approximately $7 \mathrm{~km}$ (Fig. 20, top panel). The seismic technique also captures the horizontal structure of a warm intrusion from 15-26 km (Carniel et al., 2012), as evidenced by the dark/light/ dark band reflectivity structure. The bottom panel of Fig. 20 now reveals that the top part of this intrusion was composed of diluted MLIW water ranging from 20\% to $40 \%$ in fractional value. The T-S inset in Fig. 20 for the XBT135 cast near $20 \mathrm{~km}$ further reveals that from $\sim 80-100 \mathrm{~m}$ depth the $\mathrm{T}-\mathrm{S}$ properties migrated to triangle 4 , which indicated that the water column at these 

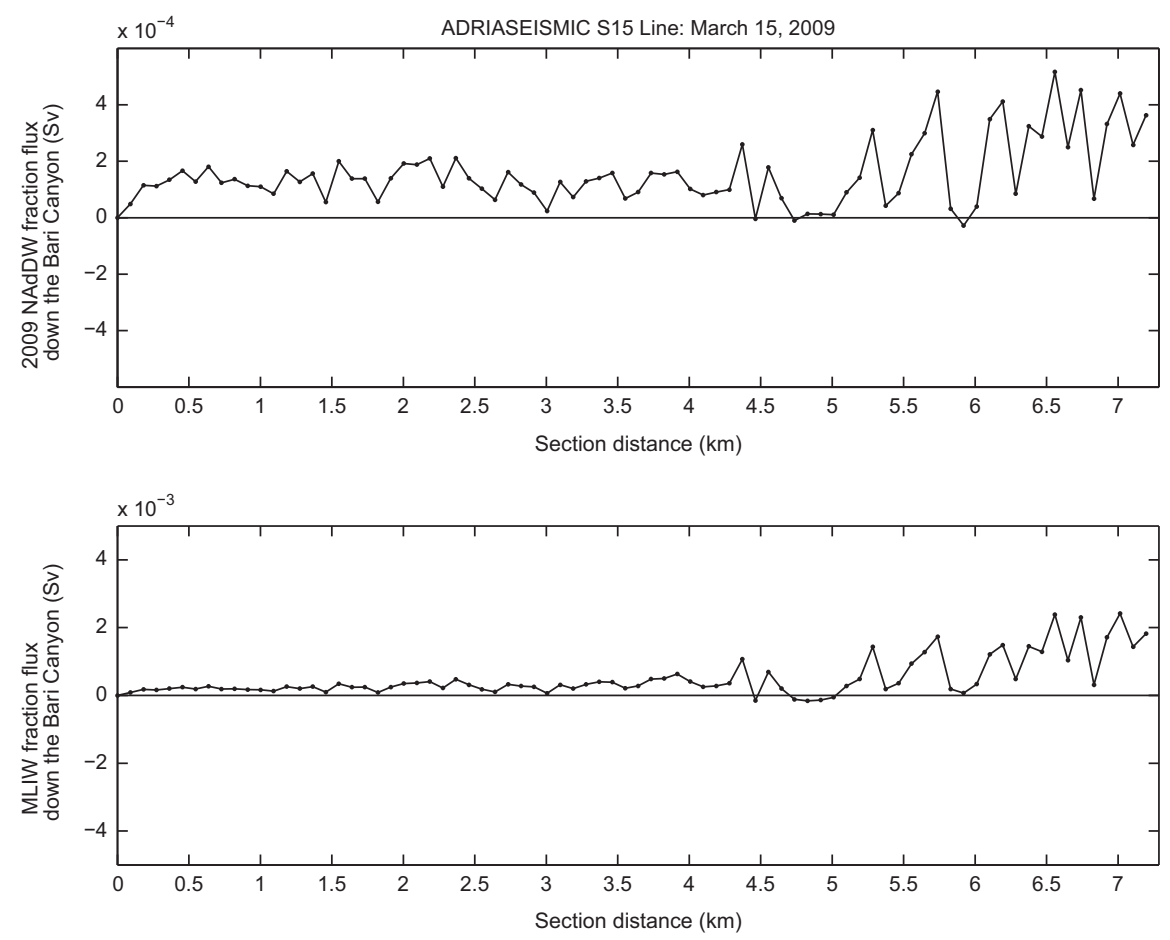

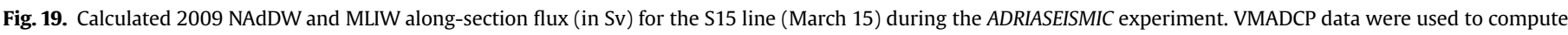
the along-section flux.

depths was actually made up of almost equal parts SW and MLIW, with no NAdDW influence, as is evident in the top panel of Fig. 20. The freshwater influence of SW in this intrusion explains why it occurred at mid-depth rather than near the seafloor.

As discussed in the previous section, current velocities in the cyclonic submesoscale eddy on this line reached $25 \mathrm{~cm} / \mathrm{s}$ (see Fig. 16). The 2009 NAdDW diluted core inshore of $10 \mathrm{~km}$ and near the $100 \mathrm{~m}$ isobath was caught in the southeastern part of the flow, while the MLIW intrusion near $10 \mathrm{~km}$ coincided with the rotating part of the eddy, and, as discussed, caused these MLIW waters to be transported towards the northwest. Similarly, velocity vectors show that the warm intrusion at $15-26 \mathrm{~km}$ composed of SW and MLIW was also transported to the west/northwest.

\section{Conclusions}

This study has identified four main source water masses in the southern Adriatic Sea in the late winter/early spring of 2009: MLIW, SW, ADW, and a warmer, lighter and fresher version of traditional NAdDW termed "2009 NAdDW", and has focused on qualitatively and quantitatively describing the mixing and transformation of 2009 NAdDW with MLIW as the former traveled south from the Gargano to the Bari region of the Adriatic Sea. As a whole, the least-square water fraction analysis technique applied to available temperature and salinity data from three back-to-back experiments has proven useful in tracking the MLIW and 2009 NAdDW pathways, particularly in a year where NAdDW production was anomalously low. Results show that despite low production, 2009 NAdDW endured its journey from Gargano to Bari. North of the Palagruža Sill, this water mass (80-90\% in fractional value) traveled southward in a non-continuous thin, dense vein between $35 \mathrm{~m}$ and $100 \mathrm{~m}$ isobaths, with diluted cores
( $>50 \%$ ) extending to $140 \mathrm{~m}$ depth, and measured fluxes along the slope ranging from -0.01 to $-0.05 \mathrm{~Sv}$. Near the Sill, 2009 NAdDW was mixed and diluted with MLIW and surface water, and by the time it reached the Bari region this source water mass was diluted to fractions of about $20 \%$. Even though the flux of 2009 NAdDW down the Bari Canyon was at least an order of magnitude smaller than the cross-section flux near Gargano, 2009 NAdDW was nonetheless observed traveling down the canyon.

The presence of the ADW source water mass was evident in casts deeper than $300 \mathrm{~m}$ in the South Adriatic Pit, although significant ADW water column fractions (of $40 \%$ and higher) were not found any shallower than $800 \mathrm{~m}$. The T-S curve from a representative station in the SAP shows two slight bends forming a salinity minimum near $750 \mathrm{~m}$ depth and a weak salinity maximum near $1000 \mathrm{~m}$ depth, and suggests the influence of a freshwater mass at $750 \mathrm{~m}$ depth and near the bottom. There is no sign of active mixing pathways occurring for these water masses during March 2009, and therefore we cannot conclude if these structures are the results of 2008/2009 water mass dynamics or residuals from dynamics of past years.

MLIW intrusions observed over the Sill and in northern sections of the study region have suggested a splitting of MLIW pathways (stemming from the main South Adriatic rim pathway) toward the central Adriatic. A major finding of this work has been the role that submesoscale eddies can play in transporting warm and salty MLIW waters towards the northwest. Northward MLIW intrusions, especially those facilitated by eddies, bring these waters into direct contact with NAdDW flowing towards the south. Source water fraction analysis shows that the boundaries between these water masses in 2009 were not generally characterized by smooth transitions, but rather by alternating peaks and minima, indicating the presence of intrusions and interleaving. These advective structures should play important roles in the dynamics of how the NAdDW and MLIW water masses mix and transform 

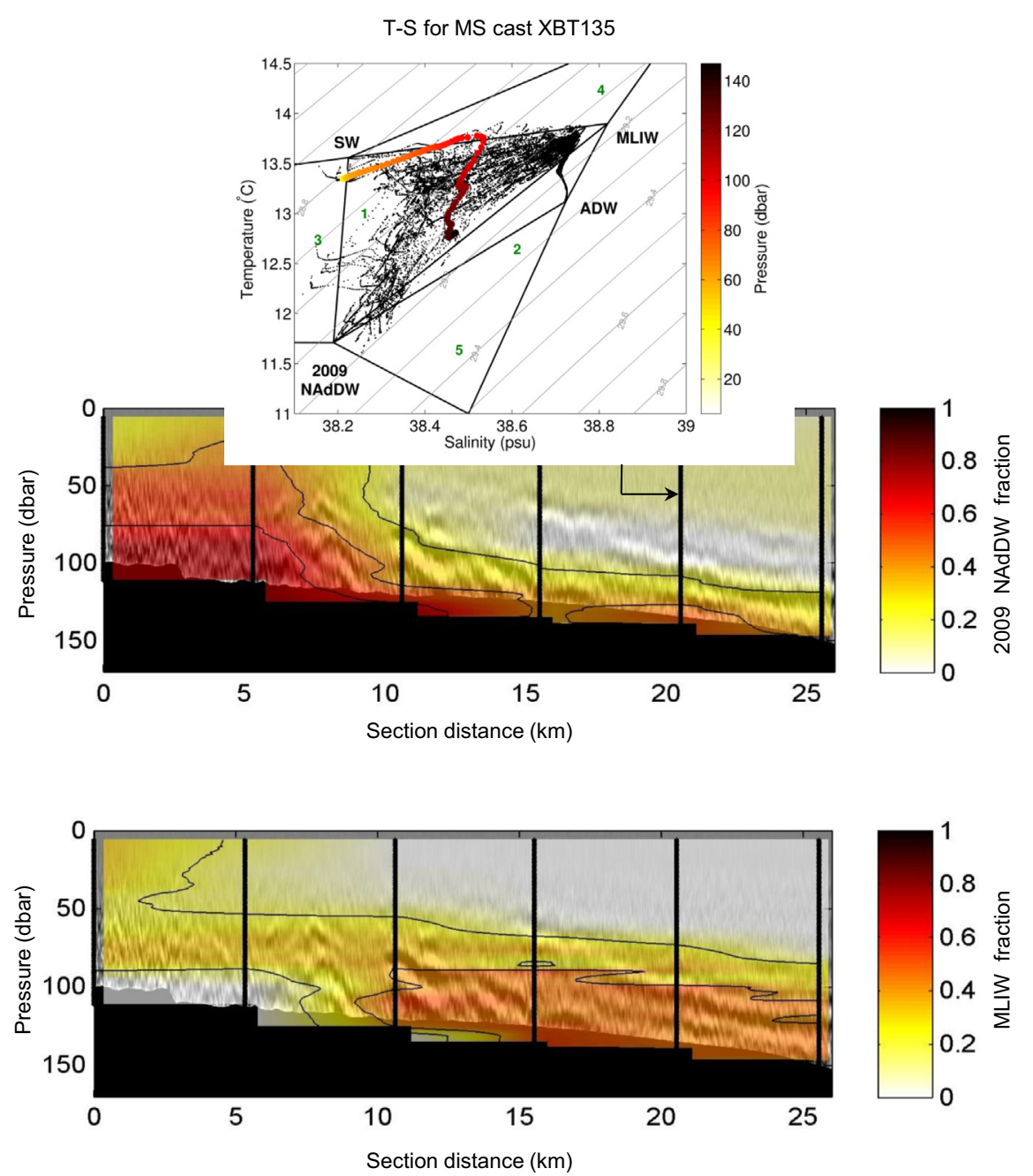

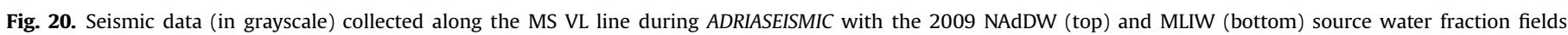

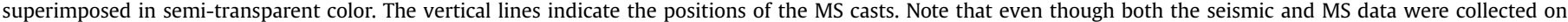

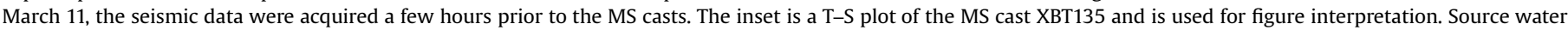

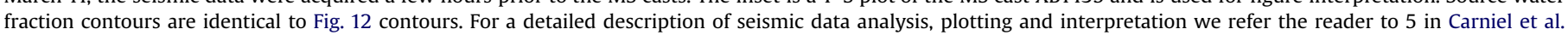
(2012), which shows the same seismic data superimposed with a simultaneous temperature field.

each other as they ultimately are transported together towards the southeast along the Adriatic continental slope.

\section{Acknowledgments}

This work was supported by the Italian National Research Council (CNR), the University of Cambridge, the University of Durham, and by the Office of Naval Research under Program Element $0601153 \mathrm{~N}$. The authors thank the crew and science team of the Italian National Research Council (CNR) R/V Urania that participated in the VELTUR09, ADRIASEISMIC, and IMPACT09 cruises. A special thank you to Dr. R. Hobbs who helped make ADRIASEISMIC possible and co-led the cruise. Thanks to the ADRIASEISMIC team and to Mireno Borghini (ISMAR, La Spezia), who collected most of the ADRIASEISMIC hydrographic data. We would also like to thank Dr. Langone (CNR-ISMAR Bologna), who coordinated the data acquisition during the IMPACT09 cruise (EUHERMIONE project, FP7-ENV-2008-1-226354), and Mr. Bortoluzzi (ISMAR Bologna), Dr. M. Ravaioli (ISMAR Bologna), Dr. Coluccelli (DISVA, Ancona) and Dr. Falcieri (DISVA, Ancona) for data acquisition during the VELTUR09 cruise ("VECTOR" project, funded by the Italian Ministry for Instruction, University and Research (Miur) through FISR 2001). Dr. Carniel acknowledges the partial support from the "FIRB" "DECALOGO" Project, code RBFR08D828, funded by the Italian MIUR.

\section{References}

Artegiani, A., Salusti, E., 1987. Field observation of the flow of dense water on the bottom of the Adriatic Sea during the winter of 1981. Oceanology Acta 10, 387-392.

Artegiani, A., Gačić, M., Michelato, M., Kovacevic, V., Russo, A., Paschini, E., Scarazzato, P., Smirccic, A., 1993. The Adriatic Sea hydrology and circulation in spring and autumn (1985-1987). Deep-Sea Research 40, 1143-1180.

Baines, P.G., Condie, S., 1998. Observations and modeling of Antarctic downslope flows: a review. In: S.S. Jacobs, S.S., Weiss, R. (Eds.), Ocean, Ice and Atmosphere: Interactions at the Antarctic Continental Margin, AGU Antarctic Research Series, vol. 75. pp. 29-49.

Bignami, F., 1990. Observations on a bottom vein of dense water in the Southern Adriatic and Ionian Seas. Journal of Geophysical Research 95 (C5), 7249-7259.

Blindheim, J., 1989. Cascading of Barents Sea bottom water into the Norwegian Sea. Rapports et Process-Verbaux des Reunions, Conseil International pour l'Exploration de la Mer 188, 161-189.

Book, J. W., Carniel, S., Bergamasco, A., Bortoluzzi, G., Hobbs, R., Matić, F., Rixen, M., Russo, A., Schroeder, K., Wood, W., 2010. A comparison study of North Adriatic Dense Water descent using observations in March, 2006 and March, 2009, Geophysical Research Abstracts, 12, EGU2010-7766-2, EGU General Assembly 2010.

Bortoluzzi, G., Del Bianco, F., Giglio, F., Riminucci, F., Coluccelli, A., Falcieri, F., Bastari, A., Giordano, G., Pacitti, D., Giordano, A., Keller, N., 2009. Crociera VELTUR09: Rapporto sulle operazioni di manutenzione boe ed esecuzione di transetti 
oceanografici in Mare Adriatico (R/V Urania, 24 Febbbraio-2 Marzo 2009). ISMAR-CNR Technical Report, 25 pp.

Burrage, D.M., Book, J.W., Martin, P.J., 2009. Eddies and filaments of the Western Adriatic current near cape Gargano: analysis and prediction. Journal of Marine Systems 78, S205-S226.

Canals, M., Puig, P., deMadron, X.D., Heussner, S., Palanques, A., Fabres, J., 2006. Flushing submarine canyons. Nature 444, 354-357.

Cardin, V., Bensi, M., Pacciaroni, M., 2011. Variability of water mass properties in the last two decades in the South Adriatic Sea with emphasis on the period 20062009. Continental Shelf Research 31, 951-965.

Carniel, S., Bergamasco, A., Book, J.W., Hobbs, R.W., Sclavo, M., Wood, W.T., 2012. Tracking bottom waters in the Southern Adriatic Sea applying seismic oceanography techniques. Continental Shelf Research 44, 30-38.

Cooper, L.H.N., Vaux, D., 1949. Cascading over the continental slope of water from the Celtic Sea. Journal of Marine Biology Association 28, 719-750.

Ellett, D.J., 1968. The cold "winter-water" of Rockall Bank. ICES CM 1968/C:24, 14 pp.

Firing, E., Ranada, J., 1995. Processing ADCP data with the CODAS software system Version 3.1. University of Hawaii, p. 206.

Foster, T.D., Carmack, E.C., 1976. Frontal zone mixing and Antarctic bottom water formation in the Southern Weddell Sea. Deep-Sea Research 23, 301-317.

Gačić, Poulain, P.M., Zore-Armanda, M., Barale, V., 2001. Chapter 1: overview. In: Cushman-Roisin, B., Gaîiić, M., Poulain, P.M., Artegiani, A. (Eds.), Physical Oceanography of the Adriatic Sea Past Present, and Future. Kluwer Academic Publishers, pp. 1-44.

Hill, A.E., Souza, A.J., Jones, K., Simpson, J.H., Shapiro, G.I., McCandliss, R., Wilson, H., Leftly, J., 1988. The Malin cascade in winter 1996. Journal of Marine Research 56, 87-106.

Holbrook, W.S., Páramo, P., Pearse, S., Schmitt, R.W., 2003. Thermohaline fine structure in an oceanographic front from seismic reflection profiling. Science 301, 821-824.

Ivanov, V., Shapiro, G.I., Huthnance, J.M., Aleynik, D.L., Golovin, P.N., 2004. Cascades of dense water around the world ocean. Progress in Oceanography 60, 47-98.

Lavin, M.F., Gaxiola-Castro, G., Robles, J.M., Richter, K., 1995. Winter water masses and nutrients in the Gulf of California. Journal of Geophysical Research 100 (C5), 8587-8605.

Langone, L., Miserocchi, S., Boldrin, A., Turchetto, M., Foglini, F., Trincardi, F., 2010. Dense water cascading bottom currents and sediment wave formation at the exit of the Bari canyon Southern Adriatic Sea Italy. Geophysical Research Abstracts 12, EGU2010-12542, EGU General Assembly 2010.

Mackas, D., Denman, K., Andrew, F., 1987. Least squares multiple tracer analysis of water mass composition. Journal of Geophysical Research 92 (C3), 8587-8605.

Manca, B.B., Kovacević, V., Gačić, M., Viezzoli, D., 2002. Dense water formation in the Southern Adriatic Sea and spreading into the Ionian Sea in the period 19971999. Journal of Marine Systems 33-34, 133-154.

Malanotte-Rizzoli, P., Hecht, A., 1988. Large-scale properties of the eastern Mediterranean: a review. Oceanologica Acta 11, 323-335.

Martin, P.J., Book, J.W., Burrage, D.M., Rowley, C.D., Tudor, M., 2009. Comparison of model-simulated and observed currents in the central Adriatic during DART. Journal of Geophysical Research 114 (C01S05), doi: http://dx.doi.org/10.1029/ 2008JC004842.

Orlić, M., Gačić, M., La Violette, P.E., 1992. The currents and circulation of the Adriatic Sea. Oceanologica Acta 15 (2), 109-124.

Pollak, M.I., 1951. The sources of the deep water in the eastern Mediterranean. Journal of Marine Research 10 (1), 128-152.
Poulain, P.M., 2001. Adriatic Sea surface circulation as derived from drifter data between 1990 and 1999. Journal of Marine Systems 29, 3-32.

Roether, W., Manca, B., Klein, B., Bregant, D., Georgopoulos, D., Beitzel, V., Kovacevic, V., Luchetta, A., 1996. Recent changes in the Eastern Mediterranean deep waters. Science 271, 333-335.

Rubino, A., Romanenkov, D., Zanchettin, D., Cardin, V., Hainbucher, D., Bensi, M., Boldrin, A., Langone, L., Miserocchi, S., Turchetto, M., 2012. On the descent of dense water on a complex canyon system in the southern Adriatic basin. Continental Shelf Research 44, 20-29.

Ruddick, B., Song, H., Dong, C., Pinheiro, L., 2009. Water column seismic images as maps of temperature gradient. Oceanography 22 (1), 192-205.

Russo, A., Bergamasco, A., Carniel, S., Grieco, L., 2011. Climatology and decadal variability of the Ross Sea shelf waters. Advances in Oceanography and Limnology 2 (1), 55-77.

Stratford, K., Williams, R.G., 1997. A tracer study of the formation dispersal, and renewal, of Levantine Intermediate Water. Journal of Geophysical Research 102 (C6), 12539-12549.

Supić, N., Vilibić, I., 2006. Dense water characteristics in the northern Adriatic in the 1967-2000 interval with respect to surface fluxes and Po river discharge rates. Estuarine, Coastal and Shelf Science 66, 580-593.

Symonds, G., Gardiner-Garden, R., 1994. Coastal density currents forced by cooling events. Continental Shelf Research 14 (2/3), 143-157.

Talley, L.D., Lobanov, V., Ponomarev, V., Salyuk, A., Tishchenko, P., Zhabin, I., 2003. Deep convection and brine rejection in the Japan Sea. Geophysical Research Letters 30 (4), 1159.

Trincardi, F., Foglini, F., Verdicchio, G., Asioli, A., Correggiari, A., Minisini, D., Piva, A. Remia, A., Ridente, D., Taviani, M., 2007. The impact of cascading currents on the Bari Canyon system, SW adriatic margin (Central Mediterranean). Marine Geology 246, 208-230.

Turchetto, M., Boldrin, A., Langone, L., Miserocchi, S., Tesi, T., Foglini, F., 2007. Particle transport in the Bari Canyon (southern Adriatic Sea). Marine Geology 246, 231-247.

Vilibić, I., Orlić, M., 2001. Least-squares tracer analysis of water masses in the South Adriatic (1967-1990). Deep-Sea Research I 48, 2297-2330.

Vilibić, I., Orlić, M., 2002. Adriatic water masses, their rates of formation and transport through the Otranto Strait. Deep-Sea Research I 49, 1321-1340.

Vilibić, I., 2003. An analysis of dense water production on the North Adriatic shelf. Estuarine, Coastal and Shelf Science 56, 697-707.

Vilibić, I., Supić, N., 2005. Dense water generation on a shelf: the case of the Adriatic Sea. Ocean Dynamics 55, 403-415.

Vilibić, I., Matijević, S., Śepić, J., Kuśpilić, G., 2012. Changes in the Adriatic oceanographic properties induced by the Eastern Mediterranean transient. Biogeosciences 9, 2085-2097.

Wang, X.H., Oddo, P., Pinardi, N., (2006-2007). On the bottom density plume on coastal zone off Gargano (Italy) in the southern Adriatic Sea and its interannual variability, J. Geophys. Res., 111, http://dx.doi.org/10.1029/2005JC003110, 112 C3.

Wust, G., 1961. On the vertical circulation of the Mediterranean Sea. Journal of Geophysical Research 66, 3261-3271.

Yoder, J., Ishimaru, T., 1989. Phytoplankton advection off the southeastern United States continental shelf. Continental Shelf Research 9, 547-553.

Zore-Armanda, M., 1974. Formation of eastern mediterranean water in the adriatic. Colloque International CNRS 215, 127-133. 